


\title{
Measurements of current penetration during PDX discharge start-up
}

\author{
D.D. Meyerhofer, R.J. Goldston, R. Kaita, A. Cavallo, B. Grek, D. Johuson, D.C. \\ McCune, K. McGuire, and R.B. White.
}

PPPL- -2169

Plasma Physics Laboratory, Princeton Liniversity

DE85 005353

P.O. 451 Princeton, NJ 08544

\begin{abstract}
The current penetration phase of PDX discharges is examined. The Fast Icn Diagnostic Experiment has been used to measure the temporal evolution of the central $q(r / a<0.4)$, and to show the effect of magnetic perturbations on fast ions. During plasma current penetration, a series of magnetic perturbations was ubserved in the plasma. If the current war riging rapidly, the perturbations were accompanied by increases in $\beta_{b}+l_{i} / 2$ and decreases in the loop voltage, suggesting a rapid penetration of the plasma current. When the plasma current was rising slowly, a series of 'minor' disruptions occurred. These were accompanied by decreases in $\theta_{b}+l_{i} / 2$ and the loop voltage, and increases in the plasma current. During this phase, current penetration may be enhanced by the change in the resistivity profile which accompanies the disruption.
\end{abstract}

\section{DISCLAIMER}

an an sponsored by an agency of the United Stales Unicd Stales Government nor any pgency therent, nor any of their

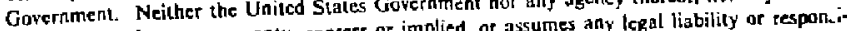

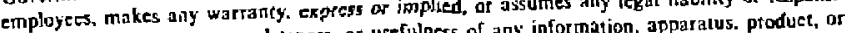
bility for the accuracy. compleleness, or usefulness of any infor privately owned rights. I.cferproess disclosed, or represents that its use woulo not infrige prively owned rese trademark, ence herein to any specific commercial producl, proces, or se imply ils endorsement, recommanufacturer, or otherwise does not necessanily constitule or imply its cndoresed. The vicws mendation. or favoring by the United States Government of any agency thereal. The views and opinions of autiors expressed hercin to not

United Siates Government of any agency thereof. 


\section{INTRODUCTION}

During the current rise phase of tokamak discharges, current penetration is sometimes found to proceed faster than would be expected for classical resistive diffusion [1 - 6]. In the ST-Tokamak[1], the initial plasma current, $I_{p,}$ was ramped in two stages. The initial rapid current rise $\left(\dot{I}_{\mathrm{p}} \approx 10 \mathrm{MA} / \mathrm{sec}\right)$ was followed by a much slower one $\left(\dot{I}_{\mathrm{p}} \approx 1 \mathrm{MA} / \mathrm{sec}\right)$. During the first phase, a hollow temperature profile was formed. This profile relaxed to a peaked profile very quickly during the second phase of the current rise. On the LT-3 Tokamak[2], current penetration was examined with magnetic probes and $X$ rays from runaway electrons. With $\dot{I}_{p} \approx 10 \mathrm{MA} / \mathrm{sec}$, a hollow current profile persisted for 500 Hsec and then rapidly filled in. During this period of rapid current penetration, rapid radial diffusion of the runaway electrons was observed. In addition, an $m / n=4 / 1$ mode was observed in the plasma, which has a non-monotcnic q-profile, with a minimum less than 4. This mode was observed before the rapid penetration began but grew rapidly once it started.

The initial stage of the discharges in the T-3 and T-4 Tokamaks were examined by Mirnov and Semenov(3). In the discharges which did not have strong radiation cooling at the edge, a series of MHD perturbations with decreasing poloidal mode number was observed while the rate of plasma current increase was roughly constant. Correlated with each of these perturbations was an outward displacement of the plasma, a positive voltage spike, and an increase in the plasma internal inductance of approximately 0.25 . Disruptive MHD activity was also observed during the plasma current rise phase in the Alcator A Tokamak|4]. With $I_{p} \approx 5 M A / s e c$, the electron temperature was found to remain peaked on the magnetic axis and a disruption was observed, with poloidal mode number $m$, when the limiter $q, q_{l}$, reached values $q_{l} \approx 1.6 \mathrm{~m}$. The early disruptions hat $\bar{B}_{\theta} / B_{\theta} \sim 0.06$, while the later ones had $\tilde{B}_{\theta} / B_{\theta} \sim 0.7$. All the disruptions showed a decrease in central electron temperature. The early disruptions showed a clear positive voltage spike and outward displacement of the plasma. The later disruptions showed an inward motion of the plasma, and a negative voltage spike preceding the pusitive one. In addition, it was found that if the current rise was slow enough for a given plasma current, no disruptions were observed. A similar experiment was recently performed on the ASDEX Tokamak[6]. It was found that the MHD activity increased with increasing rate of current rise, and in addition, the discharges with the highest rate of current rise showed the fastest current penetration. At low $\dot{I}_{p}$ the penetration was found to proceed classically, while the discharges with high $\dot{I}_{p}$ showed agreement with the model derived from the Alcator A experiment|4]. During the low $\dot{I}_{p}$ discharges, other 'glitches' were observed which did not seem to affect the classical current penetration. Hollow electron temperature profiles are also observed on the TEXT Tokamak[7] . Current penetration has been modeled with a 1-d computer code for discharges on bath PLT[5] and ALCATOR $A[4]$. In the former case, a high $Z_{e f r}$ is required to match the experimental tesults. In the latter, the experimental results can be matched if a sudden increase in the plasma resistivity and decrease in the electron temperature are applied whenever $q_{l}=1.6$. McBride et al. $[8]$ discuss various microinstabilities which have 
been suggested as the cause of the enhanced current penetration, and conclude that many of them are unlikely to occi!r.

The skin current, associated with increasing plasma current, can lead to both a hollow current and a nonmonotonic q-profile. A plasma with a hollow current profile can be unstable to 'double tearing' modes [9-14]. Mahajan and Hazeltine[15] have extended the theory and found that the 'double tearing' mode is a limiting case of one of two electromagnetic tearing instabilities, which occur in plasmas with nonmonotonic q-profiles.

If the q-profile is monotonic, but lat near the center of the plasma, the plasma can be unstable to single helicity tearing modes[9]. Disruptions associated with large single helicity islands have been studied experimentally by Robinson and McGuire[16], and theoretically by White et al-[17].

This paper reports the results of a study of current penetration in the PDX tokamak. The current penetration phase of the discharge is defined as the time from the start of the discharge until the appearance of sawteeth in th: plasma, signifying that $q(0) \leq 1[6]$. The Fast Ion Diagnostic Experiment(FIDE) $\{18$ ] was used to measure the temporal evolution of $q$ in the interior of the plasma( $r / a<0.4)$. In addition, the diagnostic was used to examine the effect of the MHD activity on parallel moving fast ions.

The PDX plasma exhibited MHD activity during the current penetration ph.tse, similar to that mentioned above, on many of its diagnostics (ECE, Sof X-ray, Mirnov loops), beginning roughly 50 msec after the plasma breakdown. Two distinct types of MHD activity were observed. While the current was increasing rapidly $\left(\dot{I}_{p} \sim 2 M A /\right.$ sec $)$, magnetic perturbations were observed to cause a rapid increase in $\beta_{\theta}+l_{i} / 2$ and the loop voltage, with a concomitant decrease in the plasma current. This is the characteristic signature of rapid current penetration $[3,4,10]$.

When the total plasma current was rising more slowly $\left(\dot{I}_{p} \sim 0.75 \mathrm{MA} / \mathrm{sec}\right)$, the $\mathrm{MHD}$ activity caused a decrease in $\beta_{\theta}+l_{i} / 2$ and the loop voltage, with an increase in the plasma current. This suggests that the current profile is broadening, and is characteristic of a 'minor' disruption $[10,16]$.

Electron temperature profiles, measured with a temporal resolution of $20 \mathrm{kHz}$ using the ECE system, showed internal MHD activity much more often than such activity was detected outside the plasma. During both types of MHD activity, there were rapid changes in the ECE temperature profile. These changes had a characteristic 'sawtooth' shape, with a decrease in temperature towards the center of the plasma and an increase towards the edge.

The large scale MHD activity observed outside the plagma was also seen on FIDE. An injected beam of parallel moving particles was observed to be dispersed in minor radius during MHD activity, suggesting that there were feld lines connecting the inner and outer regions of the plasma.

Our evidence suggests that there are two mechanisms enhancing the current penetration in PDX. When the total current is rapidly incrcased $50 \mathrm{msec}$ after breakdown, the magnetic perturbations have the effect of directly enhancing the current penetration, including changing the central $q$ value. This may be due to 'double-tearing' modes, which 
are unstable in the expected nonmonotonic q-profiles, reconnecting and redistributing the current.

When the current was increasing more slowly, the magnetic perturbations caused a broadening of the current profile, and did not change the central q-value. A 'minor' disruption may be due either to a large island caused by a single helicity tearing mode, or a saturated pair of islands caused by a double tearing mode. The effect of either would be the same. The single helicity tearing mode is unstable when the current profile is flat over the center of the plasma, and $q$ is greater than 1 in that region $[9,17]$. The 'minor' disruption caused rapid electron thermal diffusion and led to a more peaked electron temperature profile, though a decrease in the peak temperature. The current penetration is then aided by the change in the plasma resistivity profile which follows the variation in the electron temperature profile.

Section 2 of this paper cont ains a description of FIDE and presents experimental results for the current-rise phase of the discharge. Section 3 contains data from other PDX diagnostics, including electron temperature profiles from ECE and TVTS. PDX q-profiles,

calculated by the Princeton Transport Analysis Code(TRANSP)|19] from the evolution of the electron temperature profiles, are compared with the FIDE q measurements. In Sec. 4 the experimental results are discussed.

\section{DESCRIPTION OF THE q MEASUREMENT}

The Fast Ion Diagnostic Experiment(FIDE) consists of a 10 sightiine neutral particle analyser[18] and a collimated, horizontally scanning diagnostic neutral beam injec$\operatorname{tor}(\mathrm{DNB})[20]$.

The neutral particle analyser has a narrow energy bandwidth $(\Delta E / E=0.03)$ and high spatial resolution $(1.5 \mathrm{~cm})$. Neutrals emerging from PDX are ionized in a helium gas cell and energy-analysed using $127^{\circ}$ electrostatic deflection plates. They are then detected by a linear array of four $15 \mathrm{~cm} \times 1 \mathrm{c}$ m microchannel plates.

The microchannel plate detectors are divided into $0.5-\mathrm{cm}$ wide strips, each with its own anode. The signals from the microchannel plates are fed into five amplifiers, each of which is connected to six anode channels. The anodes are summed in triplets to give effectively two detectors for each amplifier, for a total of ten radially resolved simultaneous measurements. There are $\mathbf{2 0}$ radially separate slots for the amplifiers, so that the amplifiers can be packed together for high spatial resolution, or spread out to view a larger cross section of the plasma. In addition, the analyser can be scanned borizontally, so that its lines of sight can view from almost dead perpendicular to the onter edge of the plasma. The data acquisition system is capable of a sample rate of up to $20 \mathrm{kHz}$.

The diagnostic neutral beam has been operated at beam energies up to $30 \mathrm{keV}$, with $10 \mathrm{~kW}$ injected into PDX. The DNB is collimated so that it has a deposition FWH.M of $3.5 \mathrm{~cm}$. It can give a single pulse with a $40 \mathrm{msec}$ flattop, or be modulated to provide up to 100 pulses at $3 \mathrm{kHz}$. It scans horizontally, enabling it to inject at almost any radial 
Iocation in the plasma.

The analyser and injector are positioned relative to one another as shown in Fig. 1. This positioning allows the injected ions to be viewed directly by the analyser at the major radius of injection. Under normal operating conditions the ions are injected in the counter direction.

The safety factor, $q=\tau B_{\phi} / R B_{\theta}$, is measured in PDX using a method similar to that used on ATC[21]. The DNB is injected in the horizontal midplane of PDX, tangent to a magnetic fux surface. The finite pitch of the field lines causes the ions to spread over the surface, forming a 'fiery ring' in the plasma with $v_{\|} / v \approx 1$. The detector views the opposite side of the 'fery ring' in the borizontal midplane. The conservation of toroidal angular momentum,

$$
\Delta P_{\phi}=\Delta\left(m v_{\phi} R\right)+\frac{e}{c} \Delta \psi=0
$$

causes an excursion of the fast ions from the magnetic Alux surface. The poloidal flux function, $\psi$, is related to the vector potential by $\psi=R A_{\phi}$, where $R$ is the major radius of the plasma.

The drift surface is that surface formed by the circulating ions, with its axis being the drift axis. To calculate the shift of the drift axis from the magnetic axis, the Pux surfaces are assumed to be concentric tori about the magnetic axis. For $B \approx B_{\phi} \gg B_{\theta}$ and $v_{\|} \approx v_{\phi}$. the first of the two balancing terms in $\Delta P_{\phi}$ [Eq. (1)] is dominated by the change in the major radius, $\Delta R \approx \pm 2 r$, where $r$ is the minor radius of the injected particle. The sign is dependent on whether the major radius at which the particles are deposited lies inside or outside the magnetic axis.

Because $\Delta \psi=0$ on a magnetic surface, there must be a small excursion, $\Delta r$, from the surface to keep $P_{\phi}$ a constant. The poloidal fux is defined as

$$
\psi=R \int_{0}^{r} B_{0} d r .
$$

The change in $\psi$ is given by

$$
\Delta \psi \approx \frac{\partial \psi}{\partial r} \Delta r=R B_{\theta}(r) \Delta r .
$$

Using the above in Eq. (1) gives the displacement, $\delta$, of the drift axis from the magnetic axis

$$
\delta=\frac{\Delta r}{2}=\frac{v_{\|}}{\Omega_{i}} q .
$$

Here $q$ is once again the safety factor, and $\Omega_{i}=e B / m_{i} c$ is the ion cyclotron frequency.

The velocity dependence of the shift gives a straightforward method for measuring $q$. For a given accelerating potential $V$, the DNB injects ions into the plasma with energies $E=e V, e V / 2$, and $e V / 3$ (hereafter referred to as the $E, E / 2$, and $E / 3$ components). These three components follow orbits as shown in Fig. 2. The high spatial and energy resolution of our detector allows the different components to be viewed at different radii. The relative 
shift of the observed position of the three components gives us a local measurement of $q$. independent of the position of the magnetic axis.

To facilitate observation of the injected ions, the injection voltage is modulated with a square wave with frequencies between 0.5 and $3.0 \mathrm{kHz}$. By digitizing the voltage modulation along with the detector signal voltage, the beam profile can be unfolded by phaselocking the two signals. An example of the unfolded signal is shown in Fig. 3.

In some instances, the signal to noise ratios of the $E / 2$ and $E / 3$ components are too low to allow an accurate position determination. Much of this noise may be due to plasma particles of these same lower energies, which do not occur for the higher energy $E$ component. In these cases $q$ can be determined by looking at the shift of the drift axis from the magnetic axis directly. This is calculated by the simple formula

$$
\delta=R_{m a g}-\frac{\left(R_{i n j}+R_{\text {obs }}\right)}{2} .
$$

In this case, an crror is introduced due to uncertainties in the magnetic axis position.

\section{EXPERIMENTAL RESULTS}

The FIDE injector and analyser were used for a variety of different experiments, so the run time avajlable for measuring $q$ during current penetration was limited. Our experiments concentrated on measuring the temporal evolution of the central $q$. The relative lack of attenuzition, due to the low density early in the discharge, allowed sufficiently high signal levels for good temporal resolution. Figure 4 shows the injected particles viewed by the analyser; the changing flux shows that central $q$ is varying with time. The $100 \%$ modulation of the signal indicates that it is due entirely to the injected ions. In the case shown, the injection major radius was outside the magnetic axis, and the opposite side of the 'fiery ring' was observed with the analyser viewing major radii inside the magnetic axis. The peak of the signal corresponds to the 'fiery ring' having the same major radius as the viewing channel. Figure 4 shows that the minor radius at which the 'Gery ring' is seen decreases with time, which corresponds to an increase in the central current or a decrease in the central $g$, during a time when there is no large scale MHD activity in the plasma.

On three separate occasions, we made measurements of the temporal evolution of the central $q$, where 'central' means at approximately $40 \%$ of the minor radius. The measured evolution for each of the three runs is plotted in Fig. 5, along with the $q$ at the limiter, determined from the plasma current. For each platted point, the data were averaged over the 5 msec around the time indicated, to improve the accuracy of the measurement.

During current penetration, discontinuities were observed in the detected flux. An example of one of these 'glitches' is shown in Fig. 6. The plasma curreat evolution for the same shot is shown in Fig. 7. This glitch is seen on the flux of $E$ particles during the run shown in Fig. 5a. Because the degree of modulation is very similar before and after the glitch, $q$ was not dramatically changed by it. For a series of identical shots, the glitches occurred within \pm 2 msec of the same time on each shot. Similar behaviour was seen on all 
the runs shown in Fig. 5. During another run, with the plasma current evolution shown in Fig. 8 , the degree of modulation was changed by the glitch. This is shown in Fig. 9. Though the evolution of the plasma current is similar in the two cases, in the first case(Fig. 7), the glitch occurred while the plasma current was not increasing rapidly, while in the second case(Fig. 8), it occurred while the current was rising rapidly. The glitches were apparent on other diagnostics, as will be discussed below.

FIDE was used in a slightly different manner than described above, during a slow current rise case, to show that the glitch, while not rearranging the poloidal flux significantly, does allow rapid radial transport of the injected ions. This suggests that there are ergodic magnetic field lines over much of the plasma[22]. For this experiment, the injected neutral beam was not modulated but simply kept on for 20 or 30 msec. The beam ions should have been detected by the analyser only at the injection major radius and at the opposite side of their 'fiery ring' during the beam pulse. During the glitch, however, this was not the case. Figure 10 shows the effect of a glitch on the full energy beam particles $(E=27$ $\mathrm{keV}$, injected at $147 \mathrm{~cm}$ and $70 \mathrm{msec}$. The four iraces correspond to neighboring sightlines of the analyser, with the top two centered on the major radius of injection. Before the glitch, the flux is indeed centered in the top two channels, with a smaller signal in the next nearest and none in the channel viewing furthest from the injection major racius. Immediately before the glitch, there are ascillations in the detected flux. The glitch icauses a considerable increase in lux on the channel viewing furthest from the injection point, and a concomitant decrease in fux on the channels viewing the beam directly. This redistribution of particles is seen more clearly in Fig. 11. This is a compilation of two consecutive shots in order to present a view of the entire plasma. The conditions are unchanged except for the different detector viewing angles and the slightly earlier (1 msec) occuxrence of the glitch in the second shot. Figure 11 shows the beam predominantly in the channel viewing $157.3 \mathrm{~cm}$ before the glitch. During the glitch, flux appears in all of the channels, including the one viewing the center of the plasma. During the current penetration phase, the electron temperature is less than $500 \mathrm{eV}$, and since there is no auxiliary heating of the ions, it is certain that the detected flux at $27 \mathrm{keV}$ is due entirely to the particles injected by the DNB. This is very strong evidence that the glitch causes the parallel ion orbits, and presumably the field lines, to become ergodic throughout much of the plasma.

Further evidence of this is seen on the ECE electron temperature data for the run corresponding to Fig. 5b. Figure 12 shows the measured electron temperature before and after a glitch. The plasma has a low electron density during the current penetration phase, and this low opacity makes the absolute magnitude of the temperature in any of the channels uncertain, including the relationship among the channels. The relative change in time of the temperature, within a given channel, is probably meaningful. From both the TVTS electron density profile measurements and the line-averaged electron density measurements, there appears to be very little change in the density due to the glitch. Thus the changes seen on the ECE signal are probably due to electron temperature changes. After the glitch, the electron temperature profile becomes more peaked and the peak temperature is lower. This is consistent with the idea that the glitch allows enhanced 
radial heat transport loss, especially in the outer regions of the plasma.

The PDX ECE diagnostic has 10 channels which sampie at $20 \mathrm{kHz}$ through an $\mathrm{AC}$ coupled amplifier. Figure 13 shows this high temporal resolution ECE data for 80 msec of the current penetration phase. There are two glitches which appear ove: the entire radius of the plasma, hereafter referred to as global glitches, at 76 and $97 \mathrm{msec}$. Many glitches with a smaller radial extent are visible, for example at $45 \mathrm{msec}$. Many of these local glitches are seen on the ECE signal but are not present on other diagnostics. All the glitches have a characteristic 'sawtooth' shape, with a drop in the electron temperattre over the central region of the plasma and a sharp rise in the outer regions.

An oscillatory precursor can be clearly seen on some of the shots, as evident in the expanded time view in Fig. 14.

For part of one run, corresponding to Fig. 5a, the TVTS system was used to determine electron temperature and density profiles. As shown in Fig. 15, the electron temperature profiles are slightly hollow before the glitch and flatten afterwards. The TVTS system looks at a single time on any shot, so it gives only the gross temporal features.

The plasma current, loop voltage, position, and $\beta_{\theta}+l_{i} / 2$ are monitered at $10 \mathrm{kHz}$. Figure 16 shows the plasma current and $\beta_{\theta}+l_{i} / 2$ for the same shot as the ECE data in Figs. 12 and 13. Correlated with the glitches seen on the ECE data at 76 and $97 \mathrm{msec}$ are decreases in $\beta_{B}+l_{i} / 2$ and increases in the plasma current. At the same time, there is a decrease in the loop voltage and in the major radius of the plasma. This behaviour is observed in all three of the runs shown in Fig. 5 , which have $\dot{I}_{p} \sim 0.75 \mathrm{MA} / \mathrm{sec}$ at the time of the glitch.

The plasma current and $\beta_{\theta}+l_{i} / 2$ traces for another run are shown in Fig. 17, with $\dot{I}_{p} \sim 2.0 \mathrm{M} \mathrm{A} / \mathrm{sec}$. In this case there was an increase in $\beta_{\phi}+l_{i} / 2$ and decrease in the plasina current due to the glitch. At the same time, there was an increase in the loop voltage and the plasma position. In addition, the high frequency Mirnov coils[23] observed an $m / n=4 / 1$ mode in the plasma before the occurrence of the glitch at $65 \mathrm{msec}$. At the limiter $q$ was roughly 5 at this time.

The experimental run corresponding to Fig. 5a was analysed numerically using the Princeton Transport Analysis Code(TRANSP) [19]. The TVTS electron temperature(Fig. 15), electron density (Fig. 18), and the surface voltage were used as input. There is TVTS input data every $5 \mathrm{msec}$, from 50 to $100 \mathrm{msec}$. The initial current distribution was chosen by first specifying the toroidal electric field, $E_{\phi}(r)$, to satisfy

$$
\begin{gathered}
E_{\phi}(a)=\frac{V_{\text {surf }}}{2 \pi R} \\
\left.\frac{\partial E_{\phi}}{\partial r}\right|_{r=a}=\frac{1}{c} \frac{\partial}{\partial t} \frac{I_{p}}{5 a} \\
\left.\frac{\partial E_{\phi}}{\partial r}\right|_{r=0}=0 .
\end{gathered}
$$


To this $E_{\phi}(r)$ was added a perturbation,

$$
\delta F_{\phi}(\tau)=\delta_{0}\left(1-\left(\frac{r}{a}\right)^{2}\right)^{2} .
$$

The boundary conditions are unaffected by the perturbation. $\delta_{0}$ was varjed to match a specified value of $q$ at some interior point at the code start-up. For these TRANSP runs, $q(15 \mathrm{~cm})$ was chosen to be 3.2 at $50 \mathrm{msec}$ (see Fig. 5a). Because TRANSP is a cylindrically symmetric code(1-d), the measurement position is specified as the average of the injection and detection minor radii. Given the initial conditions, TRANSP advances the poloida] field according to

$$
\frac{\partial B_{\theta}}{\partial t}=\frac{\partial}{\partial r}\left\{\frac{1}{r \mu_{\eta} \sigma(r, t)} \frac{\partial\left(r B_{\theta}\right)}{\partial r}\right\}
$$

with neoclassical resistivity assumed. TRANSP solves the magnetic diffusion equation by using the input electron temperature and density data to evaluate $\sigma(r, t)$, and varies $Z_{e / f}$ to match the measured surface voltage. With neoclassical resistivity $Z_{\text {eff }}$ varied from 0.8 to 2. Thus there was no anomalously high $Z_{\mathrm{e} / f}$ which would have been expected if there had been anomalous current penetration. When Spitzer resistivity was assumed. $q(0)$ never fell below 1. This was inconsistent with the experimental observation of sawteeth, which began between 100 and 150 msec.

To compare the current distribution calculated by TRANSP to the experimental measurements, the calculated and measured values of $\Delta \psi$ were used. From the invariance of soroidal angular momentum $[E q .(1)]$, the measured $\Delta \psi$ between the injection $\left(R_{i}\right)$ and $\operatorname{detection}\left(R_{d}\right)$ major radil is

$$
\Delta \psi=\frac{c m \|_{\|}}{e}\left(R_{i}-R_{d}\right)
$$

The minor radii of injection and detcction, needed to determine $\Delta \psi_{\text {calc }}$ from TRANSP: were obtained using the calculated value of the Shafranuv shift, $\delta_{S H}(r)$, and the magnetic axis position, $\boldsymbol{R}_{m}$ :

$$
\begin{aligned}
& \tau_{i}=R_{i}-R_{m}-\delta_{S H}\left(R_{i}-R_{m}\right) \\
& r_{d}=R_{m}-R_{d}+\delta_{S H}\left(R_{m}-R_{d}\right)
\end{aligned}
$$

so that $\Delta \psi_{\text {cale }}=\psi\left(r_{d}\right)-\psi\left(r_{i}\right)$. Figure 19 shows the calculated evolution of $\psi$.

A comparison of the calculated and experimental values is shown in Fig. 20. The initial $q$ value of 3.2 at $15 \mathrm{~cm}$ was chosen for TRANSP, so that the calculated and measured values of $\Delta \psi$ would agree at $50 \mathrm{msec}$. This value was within $10 \%$ of the measured value, and hence well within the experimental error. Only the gross temporal evolution of $\Delta \psi$ could be expected from TRANSP, because there are electron temperature profiles only every $5 \mathrm{msec}$, and the ECE data shows that the profiles change on a faster time scale. This agreement between the calculated and experimental values of $\Delta \psi$ supports the conjecture that the important effect of the KiHD astivity is to redistribute the eler,tron temperature. with t! enhanced current penetration due to the change in the resistivity profile. There is also good agreement between the measured and calculated time evolutions of $\beta_{\theta}+l_{i} / 2$. 
Figure 21 shows the calculated evolution of the q-profile and the measured values of $q$ at 50 and 90 msec. During ihu MHD artivity, $q$ is calculated to be double-valued at 3, but this double-valuedness almost completely disappears by 90 r.ssec.

\section{DISCUSSION}

This section contains a brief review of theoretical work on instabilities occuring for double-valued $q$ profiles, and our views of the current penetration phase on PDX deduced from our experimental results.

Furth and coworkers[9] examined the tearing mode in a cylindrical cokamak with the definition $F=\vec{k} \cdot \vec{B}$. For the case where $F$ has two nulls in the plasma, they find that all the poloidal mode numbers $m$ are unstable. The linear analysis of double-tearing modes was exterded by Prichert et al. $[13]$. Using a two space scale analysis, they obtained a dispersion relation for the double-te sring mode. If the two rational surfaces are close together, ihe growth rate scales as $S^{-1 / 3} \tau_{a}^{-1}$, and the constant- $\psi$ approximation is not valid. A the distance between the rational surfaces increases, the constant- $\psi$ approximation becomes valid and the growth rate scales as $S^{-3 / 5}$. The magneti 2 Reynolds number, $S$, is given by $S=\tau_{r} / \tau_{a}$, where $\tau_{r}=a^{2} / \eta$ is the resistive diffusion time and $\tau_{a}=a / v_{a}$ is the Alfvén time.

Mahajan and Hazeltine[15] have studied the linear thenry of electromagnetic instabilities in plasmas with a hollow $q$ profile, and find two distinct instabilities. In a coordinate system centered at the minimum of $q, x=0$, with rational surfaces at $\pm x_{0}$, the 'binary tearing' mode is peaked at $\pm x_{0}$ while the 'centered' mode is peaked at $x=0$. It is important to note that in the 'binary tearing' case, there is no Newcomb(Ideal MHD) region between the two rational surfaces, and the 'binary-tearing' mode is a single tearing mode which tears the feeld lines at two different rational surfaces.

The stability of the 'binary-tearing' mode is determined by an effective $\Delta_{e / f}^{\prime}$

$$
\frac{1}{\Delta_{e f f}^{\prime}}=\frac{2.25}{\Delta^{\prime}}+\frac{1}{\Delta_{\text {int }}^{\prime}}
$$

where $\Delta^{\prime}$ is the usual kink-ttaring stability parameter[24],

$$
\Delta^{\prime}=\frac{\psi^{\prime}(x=+\infty)-\psi^{\prime}(x=-\infty)}{\psi_{0}}
$$

and $\Delta_{i n t}^{\prime}=\left(2.25 x_{0}\right)^{-1}$, which is always greater thar zero. When $x_{0}$ gets much larger than the resistive layer thickness and $\Delta_{e f f}^{\prime}=0$, this mode, in the next order, reduces to the standard double-tearing mode. As the distance between the rational surfaces becomes smaller than the resistive layer, the 'centered' mode becomes unstable. This mode has a larger growth rate than the 'binary-tearing' mode. This mode also tears the field lines at the rational surfaces.

Many authors $[9-12,14]$ have suggested that the reconnection assoriated with the double-tearing mode will lead to a rapid redistribution of magnetic flux and increased radial heat transpert. 
The nonlinear growth of the double-tearing mode has been examined by White et al.(11) and Carreras at al.[12]. In the nonlinear phase of the evolution, the growth rate is found to continue exponentially, rather than become linear as is the case with tearing modes associated with single magnetic islands having $m \geq 2$. The growth of the islands stops when the is]ands merge and the field lines reconnect $[11,12]$ or the islands saturate [12]. When the nonlinear evolution leads to field line reconnection, Carreras et al..[12] find that the current redistributes itself on a fast time scale, such that the q profile becomes constant in the reconnected region and bas a value slightly above $m / n$ (the value at the singular surfaces). In the saturated island case, the islands can grow large enough to overlap[12]. The saturated islands may themselves cause a minor disruption[12].

Whether the nonlinear evolution leads to saturation or field line reconnection depends on the value of the helical flux function, $\psi_{*}(r)$, at the center of the plasma and at the outermost rational surface $r_{s}$. If $\psi_{\cdot}(0) \approx \psi_{\cdot}\left(r_{a}\right)$, there will be field line reconnection; otherwise the islands will saturate.

Dnestrovskii et al.[14] have come to similar conclusions about the evolution of the magnetic islands associated with nonmonotonic q profiles. They find that the islands evolve in one of two diferent manners, depending on the amount of poloidal magnetic Hux(the magnetic 'barrier') between the resonant surfaces. If the magnetic ba.rier is low, the islands are found to reconnect(mix) on a fast time scale. If the magnetic barrier is large enough, the islands exist independently, with the outer growing towards the plasma edge and the inner growing towards the center of the plasma.

The case of $F$ having a single null in the plasma was also considered by Furth et al., [9]. They found that their 'flattened model' for the current profile is more unstable than their 'peaked model.' White et al.[17] have numerically examined the full nonlinear evolution of these tearing modes for a current profile, which has a tlat q profile in the center of the plasma with $1<q(0)<2$. They have followed the evolution of the $m=2$ mode, and find that the $m=2$ island evolves to a very large size. They speculate that these large islands may be the cause of 'major' tokamak disruptions.

Stix[10] has examined magnetic reconnection associated with both hollow and monotonic current profiles by examining the interaction of two current shells in the plasma. If the inner shell is carrying more current(monotonic profile), the reconnection will lead to a decrease in the plasma inductance, a negative voltage spike, and an increase in the total current. If there is more current carried in the outer shell, then the reconnection causes an increase in the inductance and loop voltage, and a decrease in the plasma current.

Most of our experimental q data come from the phase of the discharge when the total current is not changing rapidly. During this phase, there is no evidence of a rapid change in the central $q$ value due to the glitck, even though the central $q$ value is changing in time. For early times ( $t \leq 50 \mathrm{msec}$ ), as in Fig. $5 \mathrm{a}$, there is no large scale MHD activity, even though the plasna current is changing rapidly. The central-q value is changing rapidly as well, as is shown in Fig. 4.

Our evidence suggests two different processes for current penetration in PDX. When the current is rising rapidly, there is probably a hollow current profile which would be 
unstable to double-tearing modes. These modes aid the current penetration due through their reconnection, and lead to more flattened current profiles. The reconnection should be expected to change the q profile on a fast time scale.[12]

When the plasma current is increasing slowly, the plasma relaxes towards its steady state by a series of 'minor' disruptions. These enhance the current penetration by changing the resistivity profile, through a change in the temperature profile and possibly an increase of the impurity content in the plasma. This current penetration can be modelled assuming neoclassical resistivity, and using the measured electron temperature profiles.

It is impossible to tell from our data whecher the 'minor' disruptions are caused by a single island or a saturated pair of islands. The inversion radius for these global glitches is near the edge of the plasma(Fig. 10), and the most dramatic redistribution of the temperature occurs in the outer region of the plasma. In a plasma with a nonmonotonic current. profile, the minor radius of the maximum current density is less than that corresponding to the minimum of $q[12]$, so that the outer rational surface is always in a region where the current is decreasing. Thus the effect of a minor disruption caused by a large single helicity island and that caused by the outer of two saturated islands should be the same.

Granetz et al. [4] found that the electron temperature can remain peaked on axis even as hollow current profiles exist in the plasma, so that the temperature profile cannot be used to determine whether there are single or double islands.

The $q$ profiles calculated by TRANSP(F:g. 17), which are in reasonable agreement with the data, suggest that the global glitches may be caused by a saturated pair of islands earlier and by a single helicity island later, during the period when the total current is not changing rapidly.

It is possible that the minor glitches seen on the ECE measurement are associated with the 'centered' mode, predicted by Mahajan and Hazeltine[15].

\section{CONCLUSION}

The data presented in this paper suggest a two stage process for the evolution of the current profile during the current penetration phase of the PDX discharge. Many of the characteristics of current penetration, observed in previous experiments, are present in PDX. We are able to suggest two scenarios for current penetration in the PDX tokamak.

When the total plasma current was increasing rapidly, the current penetration was enhanced directly by magnetic perturbations. These may be caused by the reconnection of islands associsted with double-tearing modes.

When the total plasma curront was rising slowly, the current penetration is enhanced by changes in the plasma resistivity profile caused by 'minor' disruptions. These may be caused by safurated 'double-tearing' islands, or by a single helicity island. 


\section{ACKNOWLEDGMENTS}

We would like to thank Dr. Kees Bol and the PDX group for making these experiments possible, and Dr. Hironori Takahashi for many useful discussions. One of us(R.J.G.) would like to thank Dr. Harold Eubank for the suggestion that the PDX FIDE q-measuremcnt technique could be well suited to studying current penetration during start-up.

This work was supported by the United States Department of Energy Contract No. DE-ACO2-76-CHO-3073. 


\section{REFERENCES}

\section{Bibliography}

[1] DIMOCK, D.L., EUBANK, H.P., HINNOV, E., JOHNSON, L.C., MESERVEY, E.B., Nucl. Fusion 13 (1973) 271.

[2] HUTCHINSON, I.H., MORTON, A.H., Nucl. Fusion 16 (1976) 447.

[3] MIRNOV, S.V., and SEMENOV, I.B., Sov. J. Plasma Phys. 4 (1978) 27.

(4) GRANETZ, R.S., HUTCHINSON, I.H., OVERSKI, D.O., Nucl. Fusion 19 (1979) I587.

(5) HAWRYLUK, R.J., BRETZ, N., DIMOCK, D., HINNOV, E., JOHNSON, D., MONTICELLO, D., MCCUNE, D. and SUCKEWER, S., PPPL-1572(1980).

[6] KARGER K., KLUEBER O., NIEDERMEYER H., SCHUELLER F.C., THOMAS P.R., Post-deadline Payer, A10 11th European Confereace on Controlled Fusion and Plasma Physics, AACHEN F.R.G. 5-9 Sept 1983.

[7] MCCOOL, S.M., PhD thesis, University of Texas, Austin (1983).

[8] MCBRIDE, J.B., KLEIN, B.H., BYRNE, R.N., KRALL, N.A., Nucl. Fusion 15 (1975) 393.

[9] FURTH, H.P., RUTHERFORD, P.H., SELBERG, H., Phys. Fluids 16 (1973) 1054.

[10] STIX, T.H., Phys. Rev. Lett. 36 (1976) 521.

[11] WHITE, R.B., MONTICELLO, D.A., ROSENBLUTH, M.N., WADDELL, B.V., in Plasma Physics and Controlled Nuclear Fusion Research(Proc. 6th Int. Conf. Derchtesgarden 1976) vol.1, LAEA, Vienna (1977)569.

[12] CARRERAS, B., HICKS, H.R., WADDELL, B.V., Nucl. Fusion 19 (1979) 583.

[13] PRICHERT, P.L., LEE, Y.C., DRAKE, J.F., Phys. Fluids 23 (1980) 1368.

(14) DNESTRovSKII, Y.N., Kostomarov, D.P., POPOV A.M.. Sov. J. Plasma Phys. 5 (1979) 289.

[15] MAHAJAN, S.M., HAZELTINE, R.D., Nucl. Fusion 22 (1982) 1191.

[16] ROBINSON, D.C., McGUIRE, K., Nucl. Fusion 19 (1979) 115.

[17] WHITE, R.B., MONTICELLO, D.A., ROSENBLUTH, M.N., Phys. Rev. Lett. 39 (1977) 1618. 
[18] KAITA, R., GOLDSTON, R.J., ERIDON, J., MEYERHOFER, D.D.. Rev. Sci. Instrum. 52 (1980) 1795.

[19] HAWRYLUK, R.J., in Physics of Plasmas Close to Thermonuclear Conditions, Varenna. (1979) 19 .

[20] INUDELMAN, A. et. al, J. Vac. Sci 20 (1982) 1218.

[21] GOLDSTON, R.J., Phys. Fluids 21 (1978) 2346.

[22] GOLDSTON R.J., KAITA, R., MEYERHOFER, D.D., Bull. Am. Phys. Soc. (1983).

[23] HAMMETT, G., MCGUIRE, K., PPPL-1854(1982).

[24] FURTH, H.P., KILlEEN, J., ROSENBLUTH, M.N., Phys. Fluids 6 (1963) 459. 


\section{FIGURE CAPTIONS}

Fig. 1 Overhead view of PDX, showing the relative positions of the FIDE detector and injector(DNB).

Fig. 2 Orbits for particles with $v_{\|} / v \sim 1$, born inside or outside the magnetic axis in major radius, at the three DNB injection energies.

Fig. 3 Meastred shape of the circulating ion beam.

Fig. \& Modulated detected flix of the circulating ion beam at $R=99 \mathrm{~cm}(\mathrm{a})$ and $R=$ $107.5 \mathrm{~cm}(\mathrm{~b})$, shor ag radial movement during current penetration.

Fig. 5 Measured values of central $q(\bullet)$ during the current penetration phase of the PDX discharge. Also shown is the evolution of $q$ at the edge of the plasma( $\Delta)$.

Fig. 6 The effect of a glitch at $80 \mathrm{msec}$ on tbe modulated full energy fux.

Fig. 7 Evolution of the plasma current during the shot shown in Fig. 6.

Fig. 8 Evolution of the plasma current during the shot shown in Fig. 9.

Fig. 9 Oscilloscope traces, showing the effect of a glitch at $62 \mathrm{msec}$ on the modulated one-third energy flux, at major radii $R=116.7,119.0,121.4,123.8,126.1 \mathrm{~cm}$. The injected neutral beam $(R=144.8 \mathrm{~cm})$ was modulated.

Fig. 10 Oscilloscope traces showing the effect of the glitch on the detected full energy flux at major radii $R=145.1,147.3,149.5,151.6,153.7 \mathrm{~cm}$. The injected neutral beam $(R=146 \mathrm{~cm})$ was not modulated in this case.

Fig. 11 Detected Hlux from consecutive shots, showing that the glitch causes injected ions to appear over the entire plasma.

Fig. 12 ECE electron temperature profiles before(a) and after(b) the glitch at 76 msec.

Fig. 19 Fast ECE channels with global glitches at 76 and $97 \mathrm{msec}$.

Fig. 14 Fast ECE channels showing the oscillatory precursor of the glitch.

Fig. 15 TVTS electron temperature profiles before(a) and after(b) the glitch at $80 \mathrm{msec}$.

Fig. $16 \beta_{\theta}+l_{i} / 2(a)$ and $V_{\text {loop }}(\mathrm{b})$ during current penetration, with $\partial I / \partial t \sim 0$.

Fig. $17 \beta_{\theta}+l_{i} / 2(\mathrm{a})$ and $V_{\text {loap }}(\mathrm{b})$ during current penetration, with $\partial I / \partial t>0$.

Fig. 18 TVTS electron density profile used as input for TRANSP.

Fig. 19 The evolution of the $\psi$-profiles calculated by TRANSP. 
Fig 20 Measured values of $\Delta \dot{\psi}(\bullet)$ and those calculated by $\operatorname{TRANSP}(\Delta)$.

Fig. 21 The evolution of the q profiles calculated by TRANSP. The measured values of $q$ at $50 \mathrm{msec}(\mathrm{A})$ and $90 \mathrm{msec}(B)$ are included for comparison. 


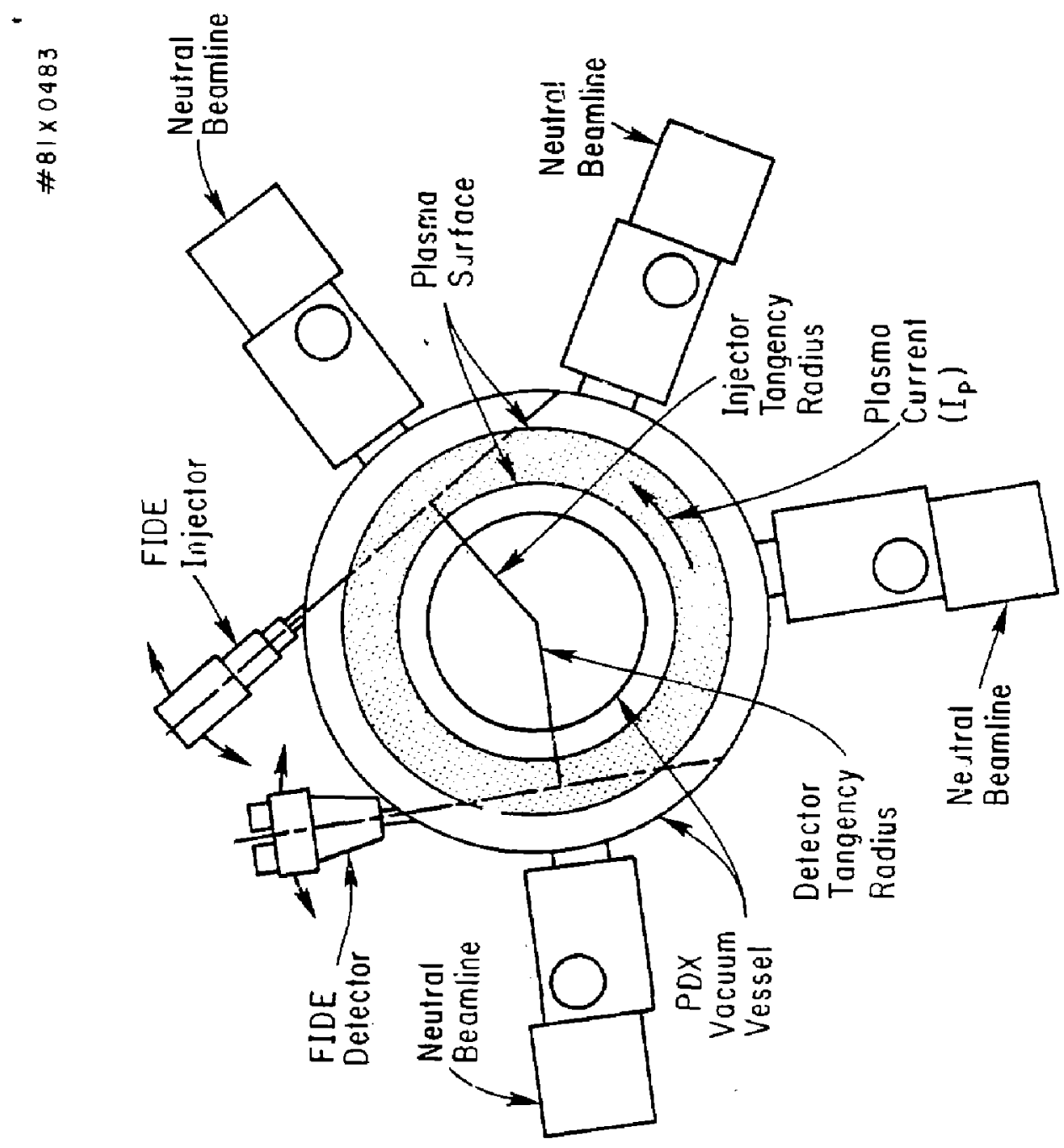


$\# 82 \times 1011$

ORBIT SHIFTS FOR COUNTER INJECTION

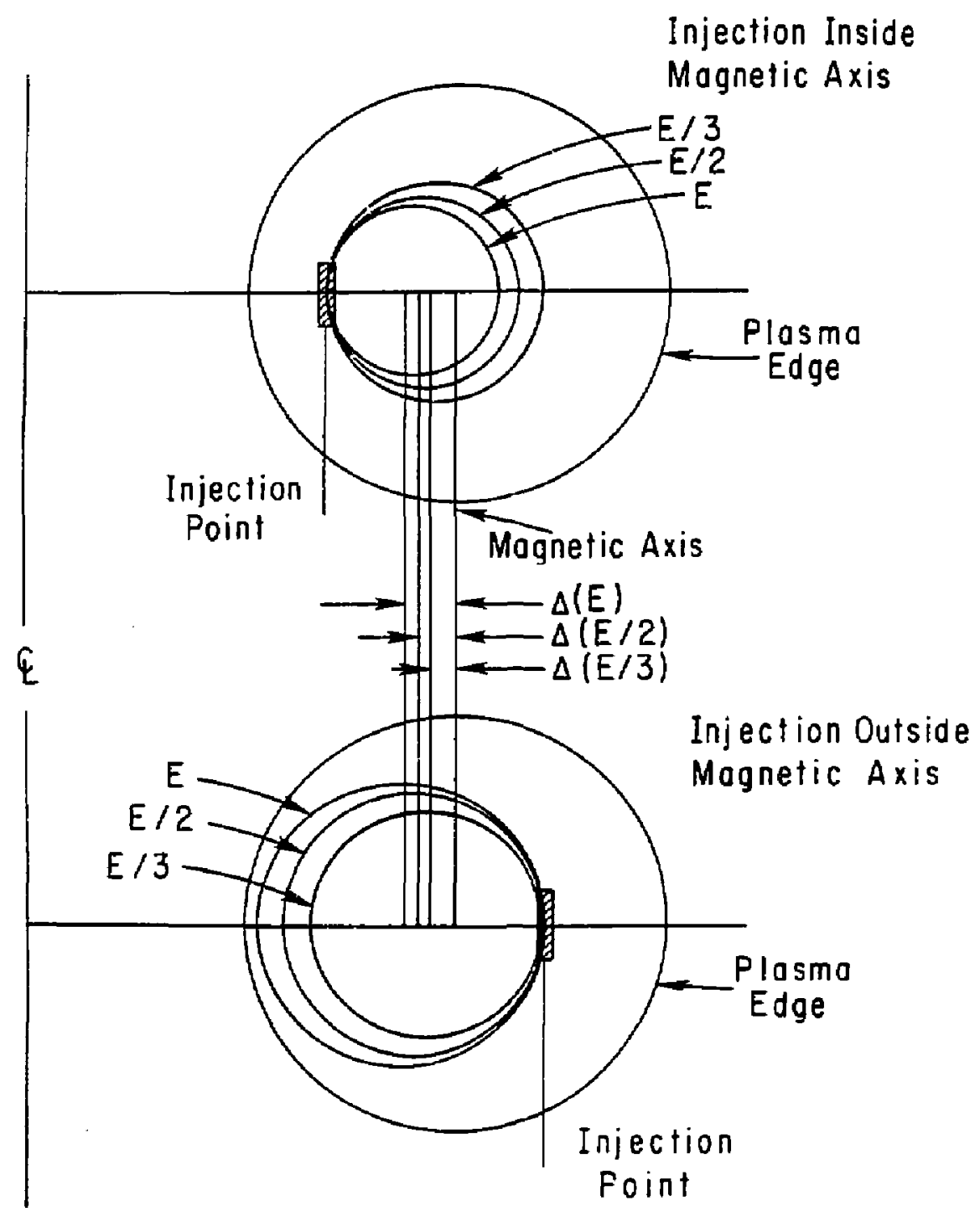




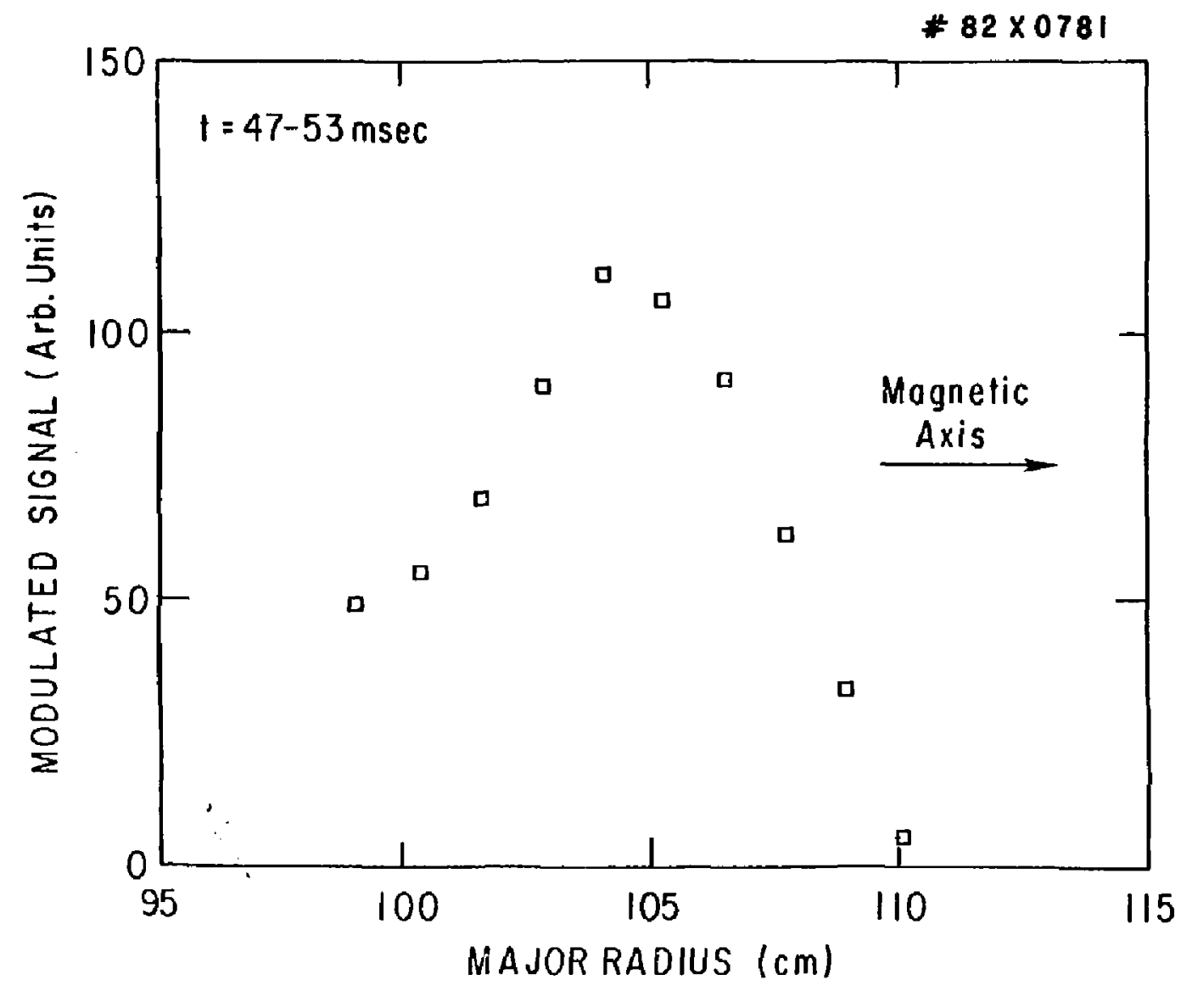




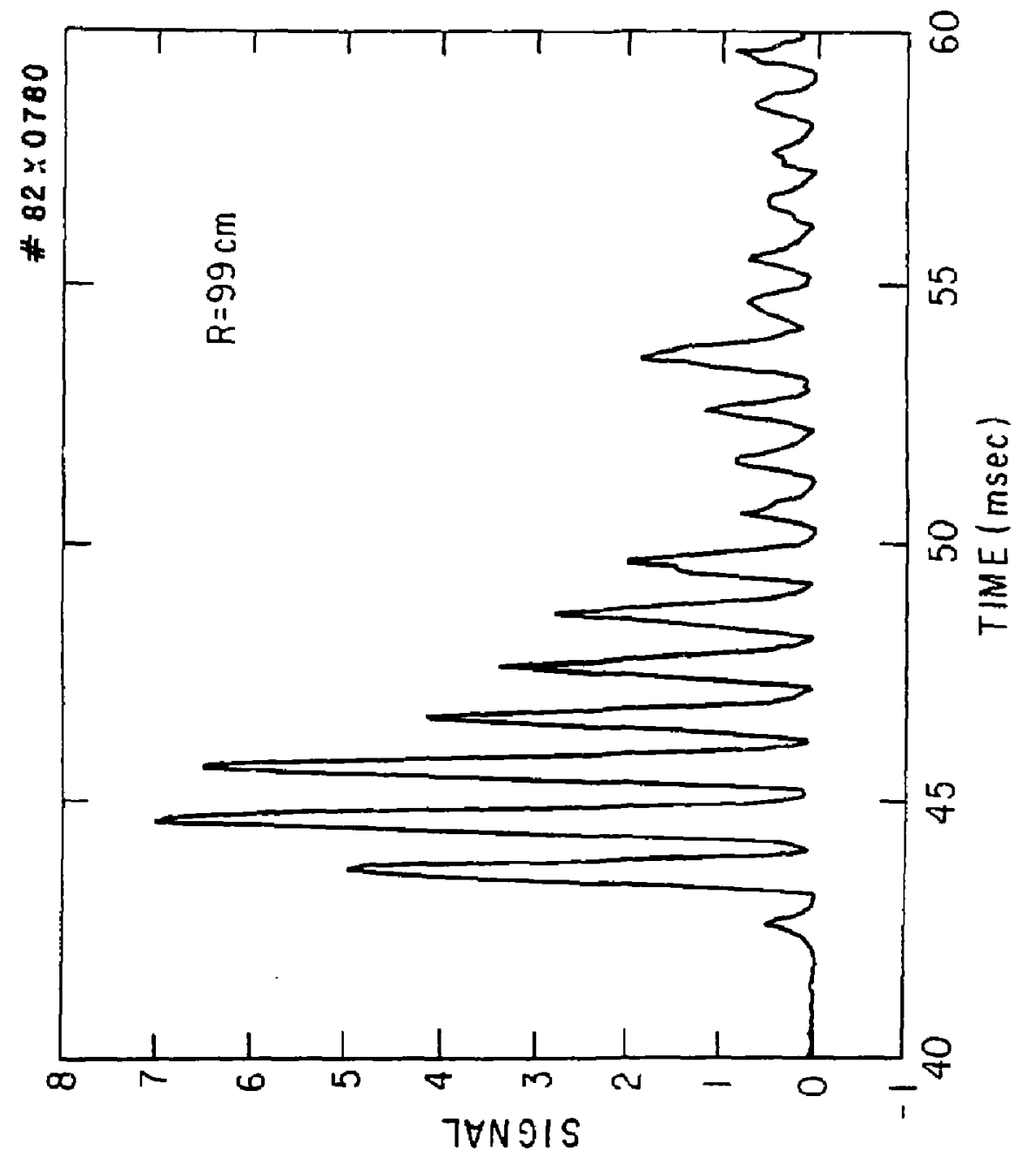




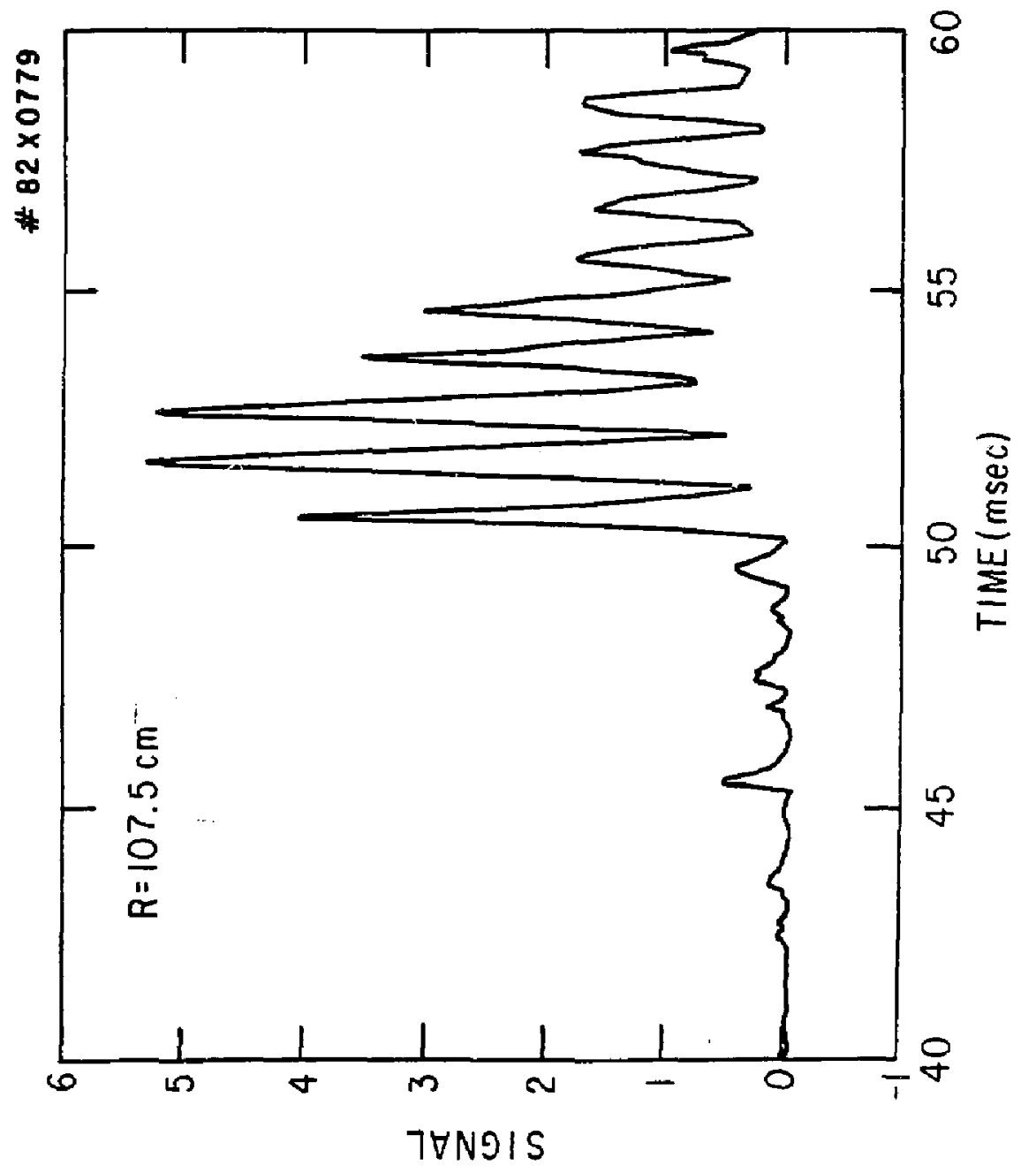

$E$
$\dot{\sigma}$
$\dot{5}$ 

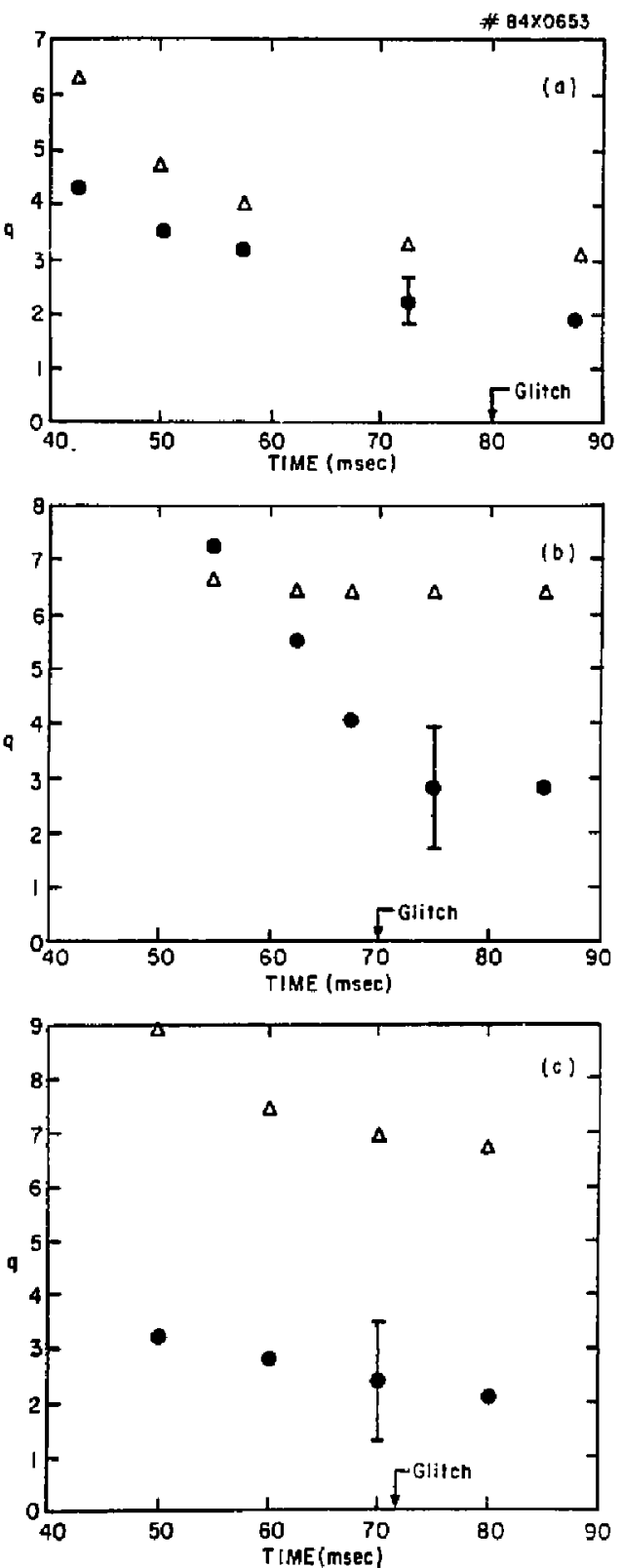

Fig. 5 


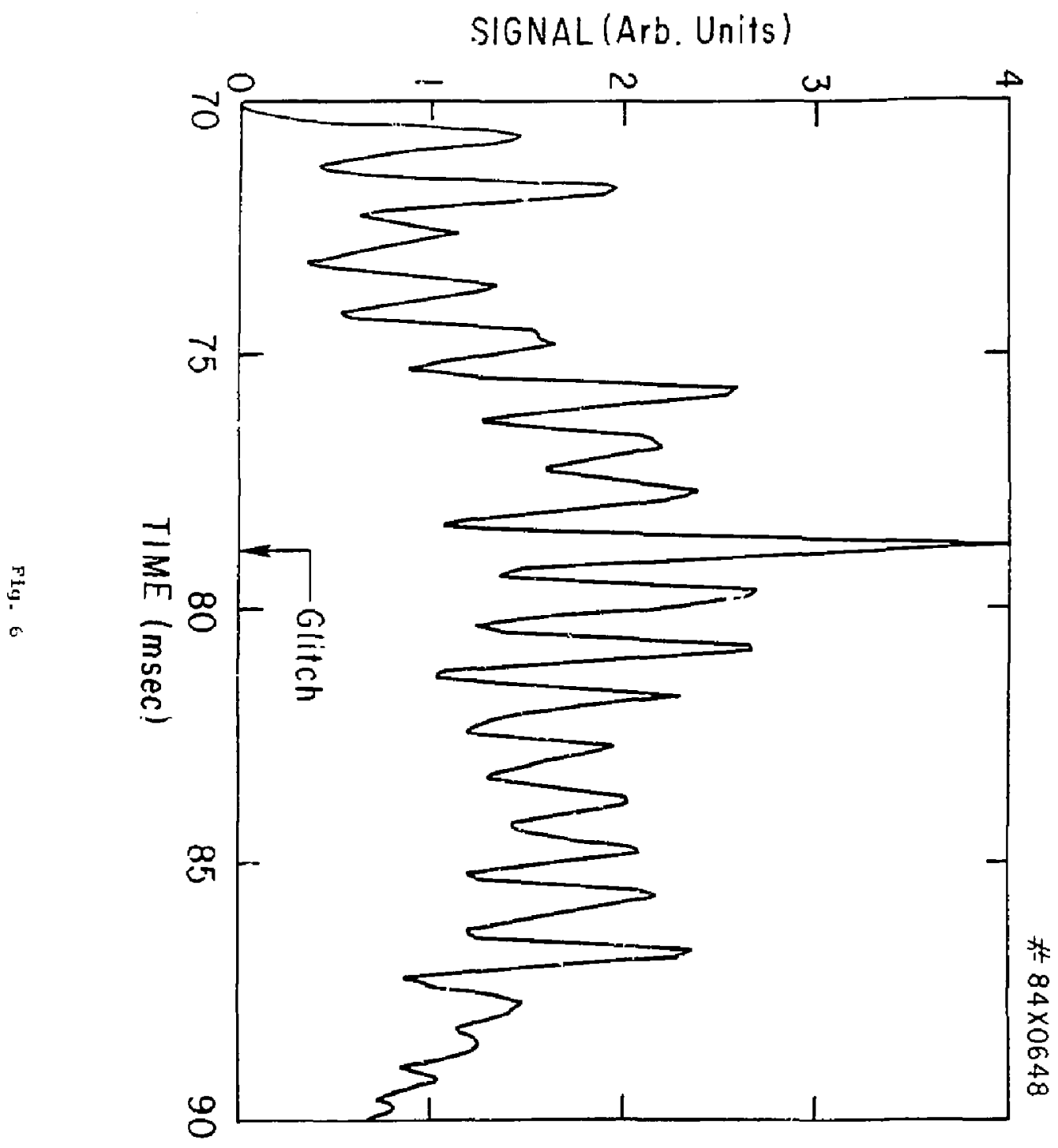




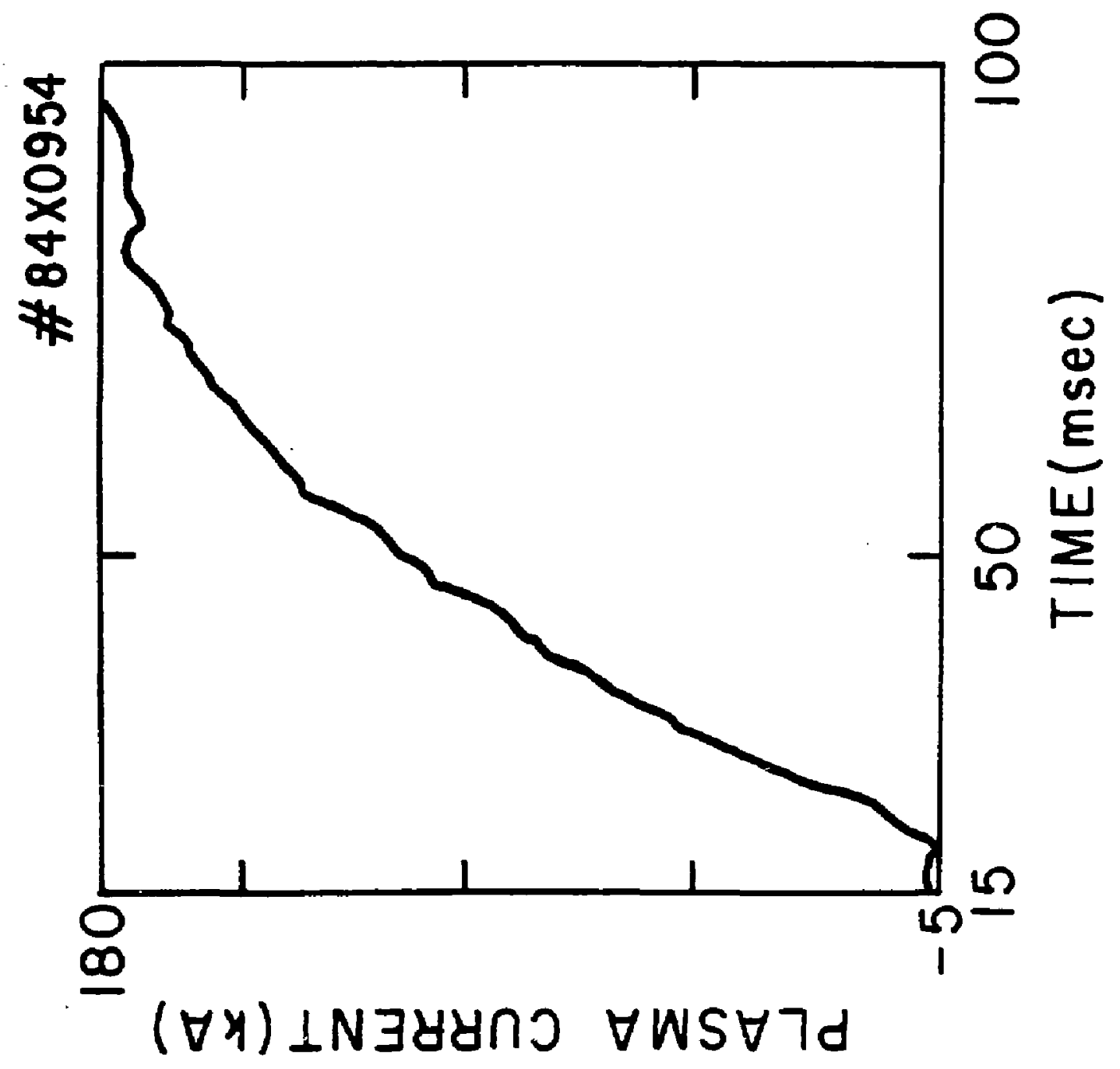

Fig. 7 
PLASMA CURRENT (KA)

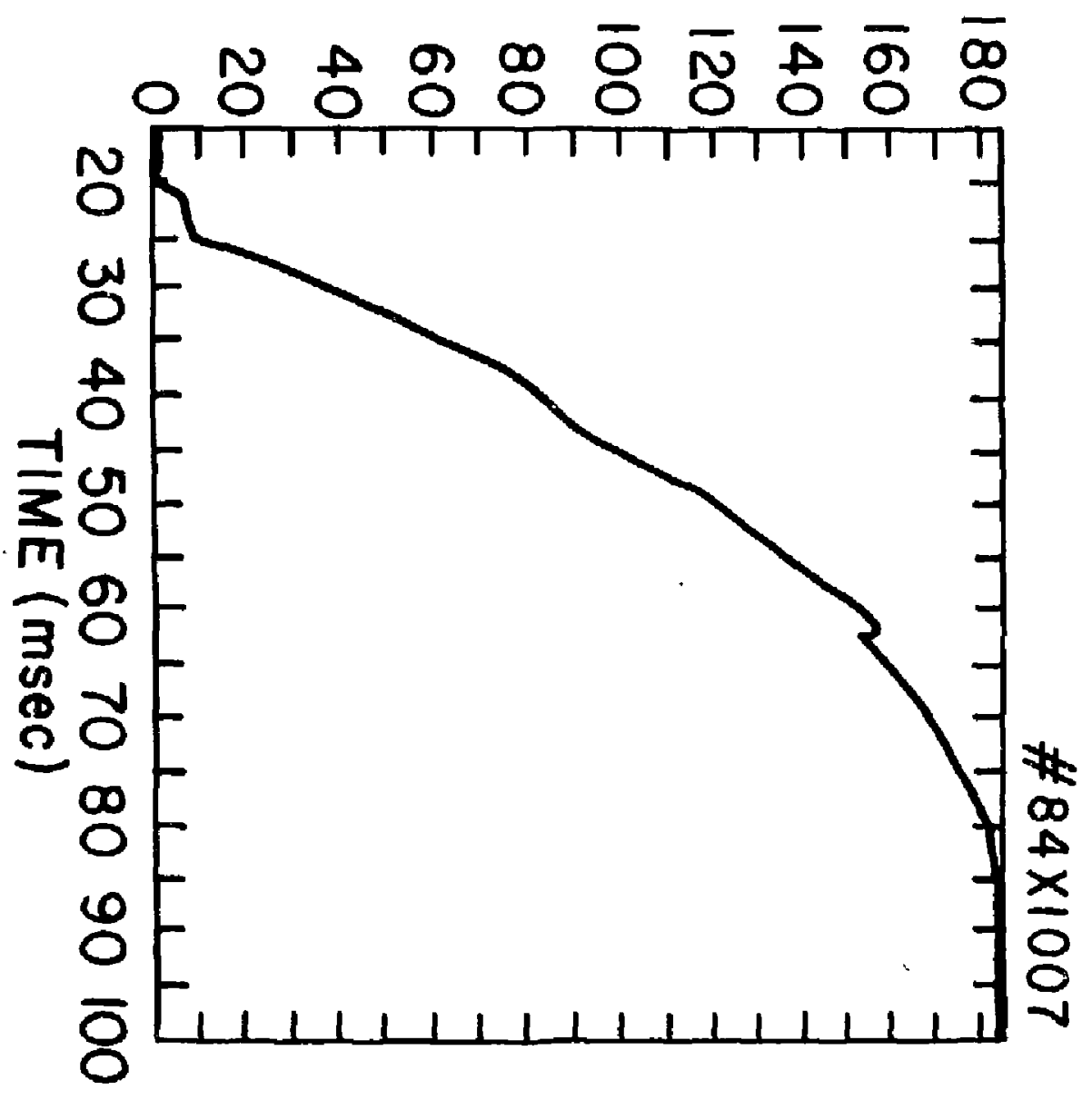



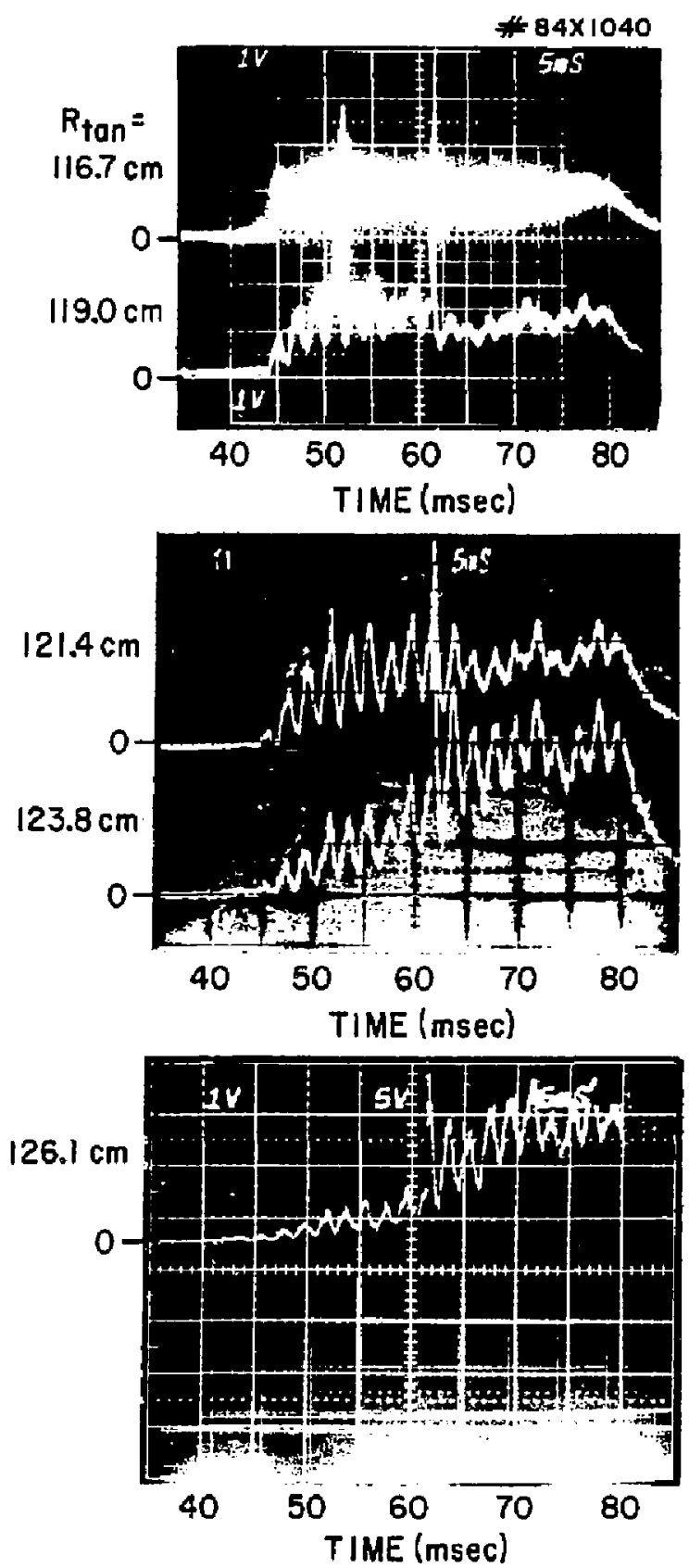

Fig. 9 

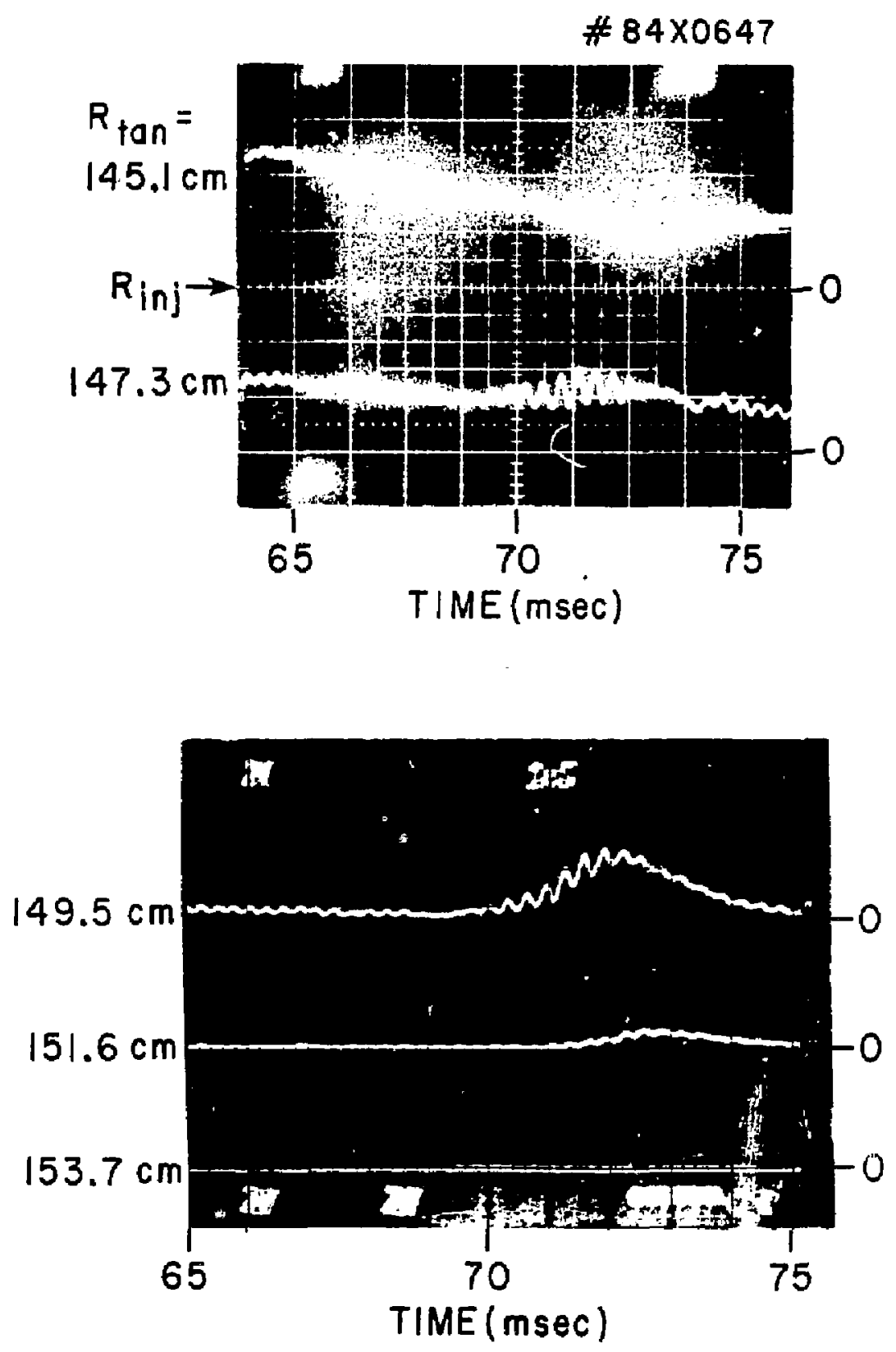

Fig. 10 


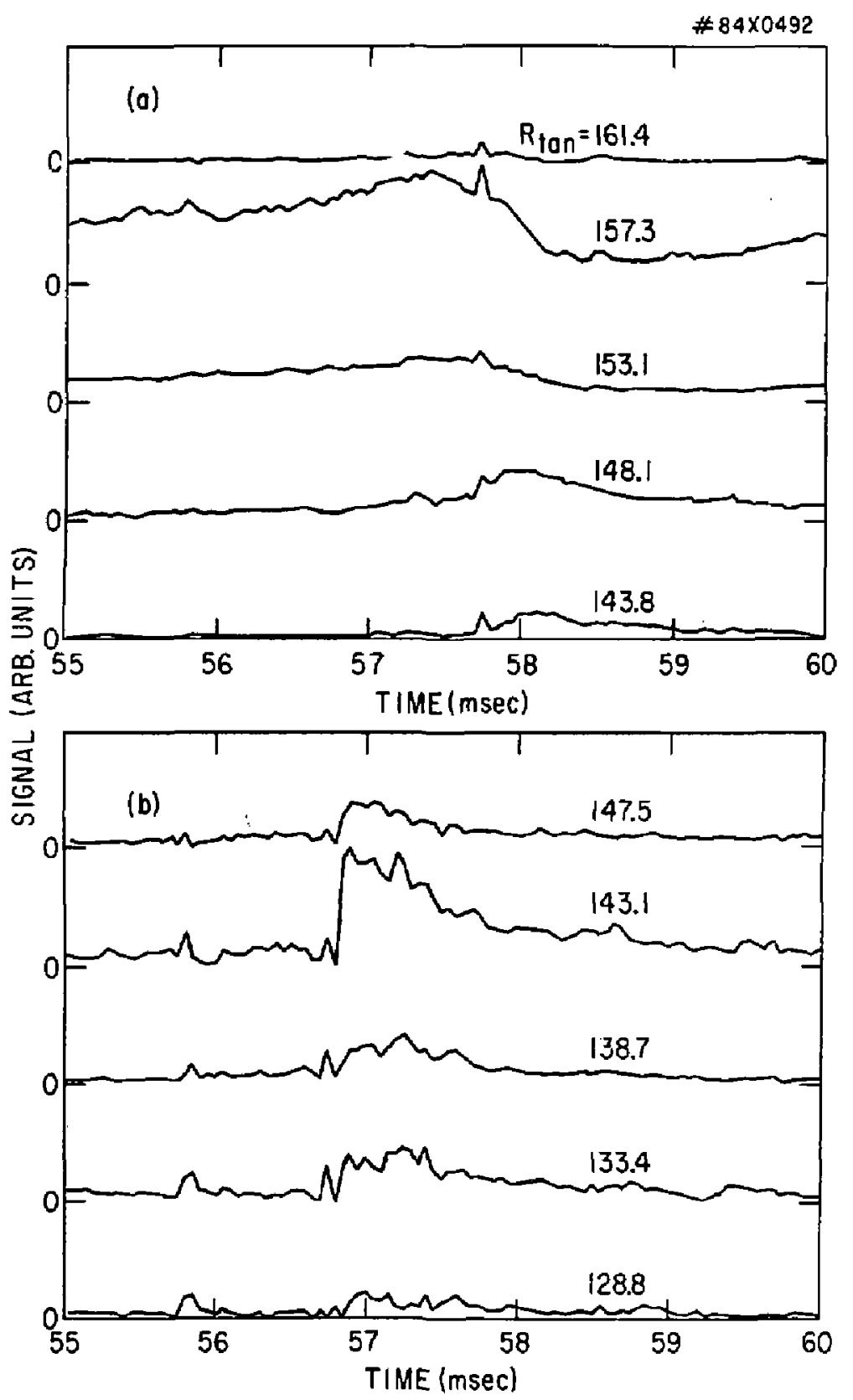

FIg. 11 

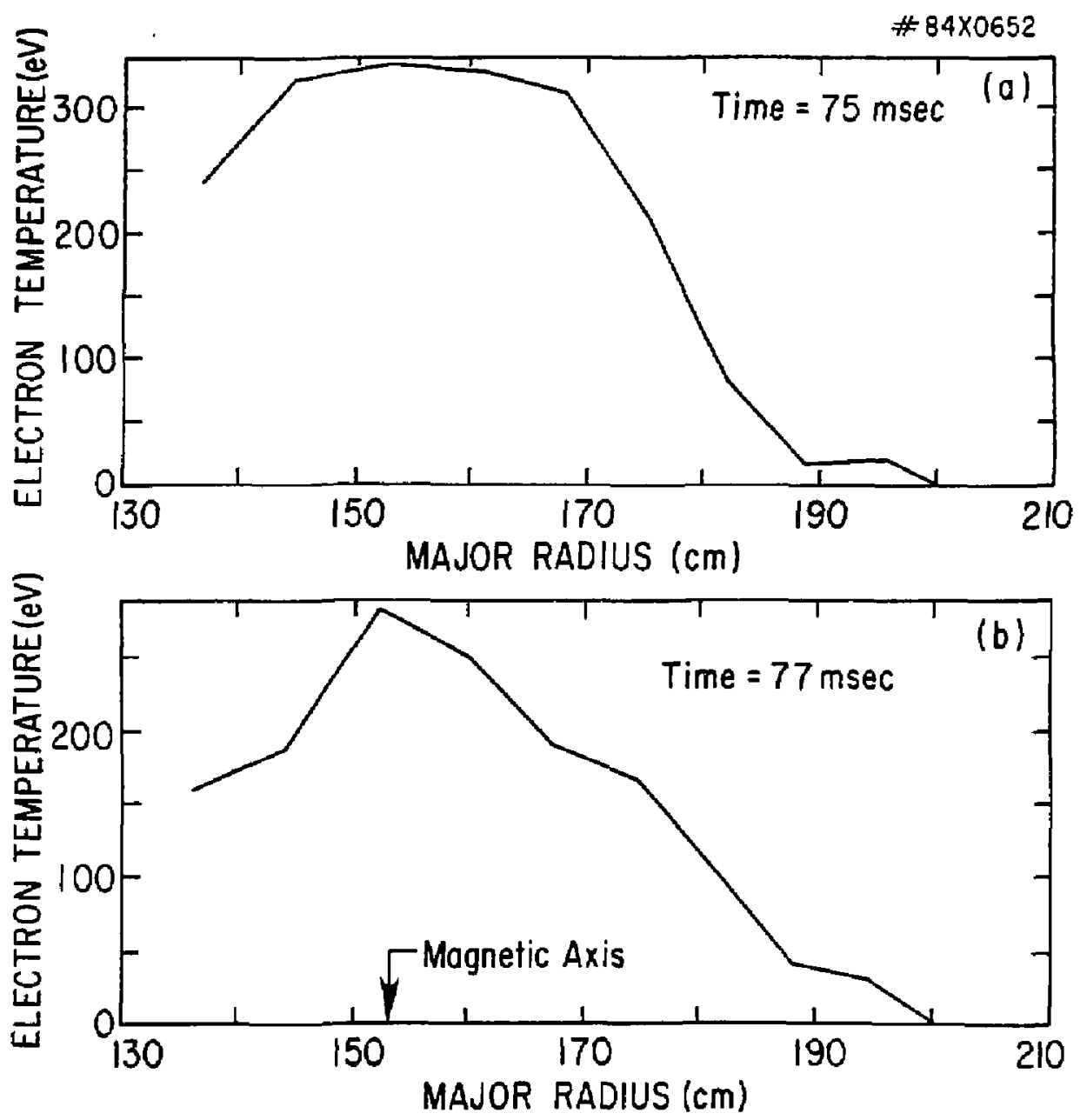

Fig. 12 

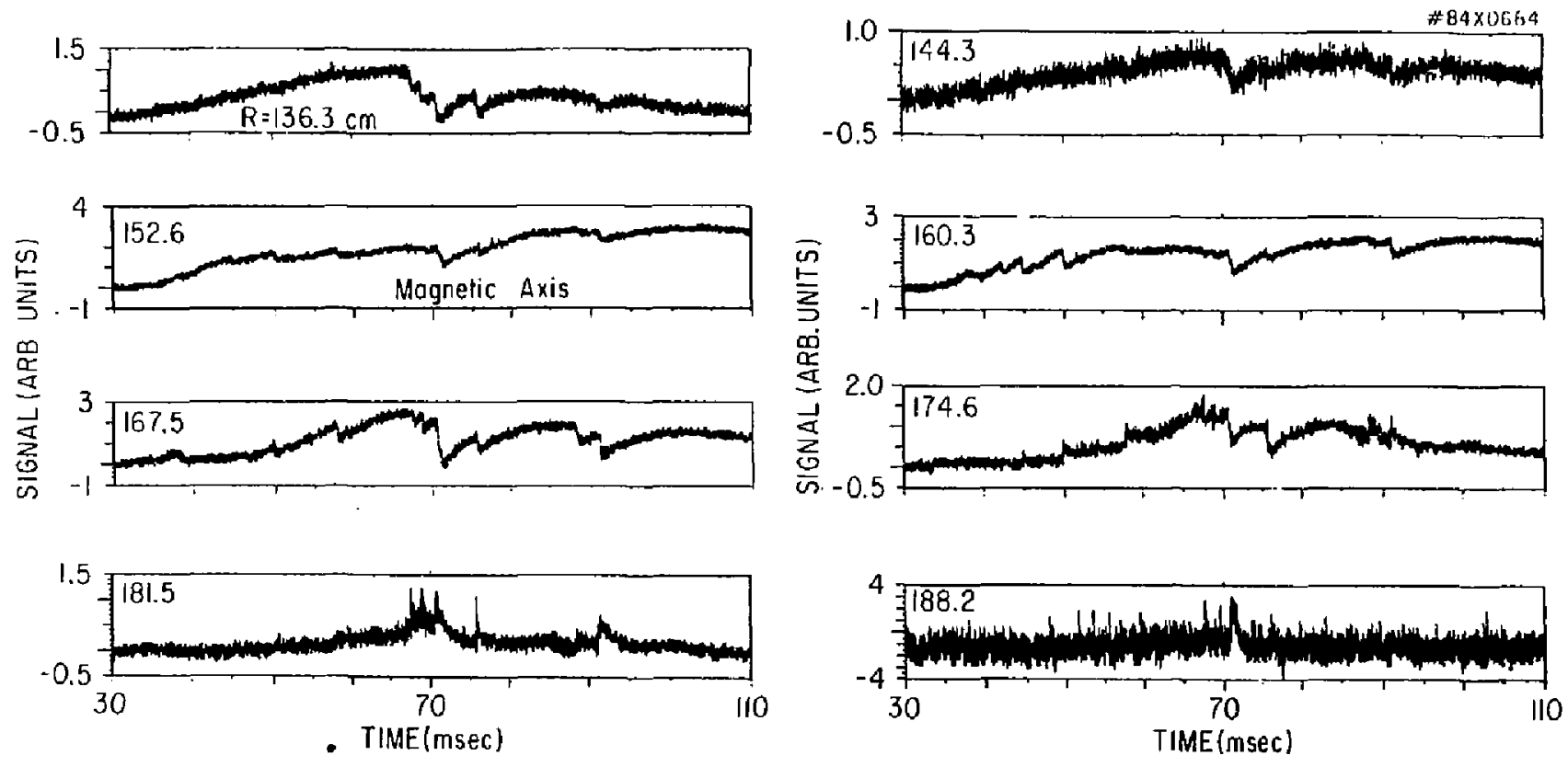
\# 84X0651

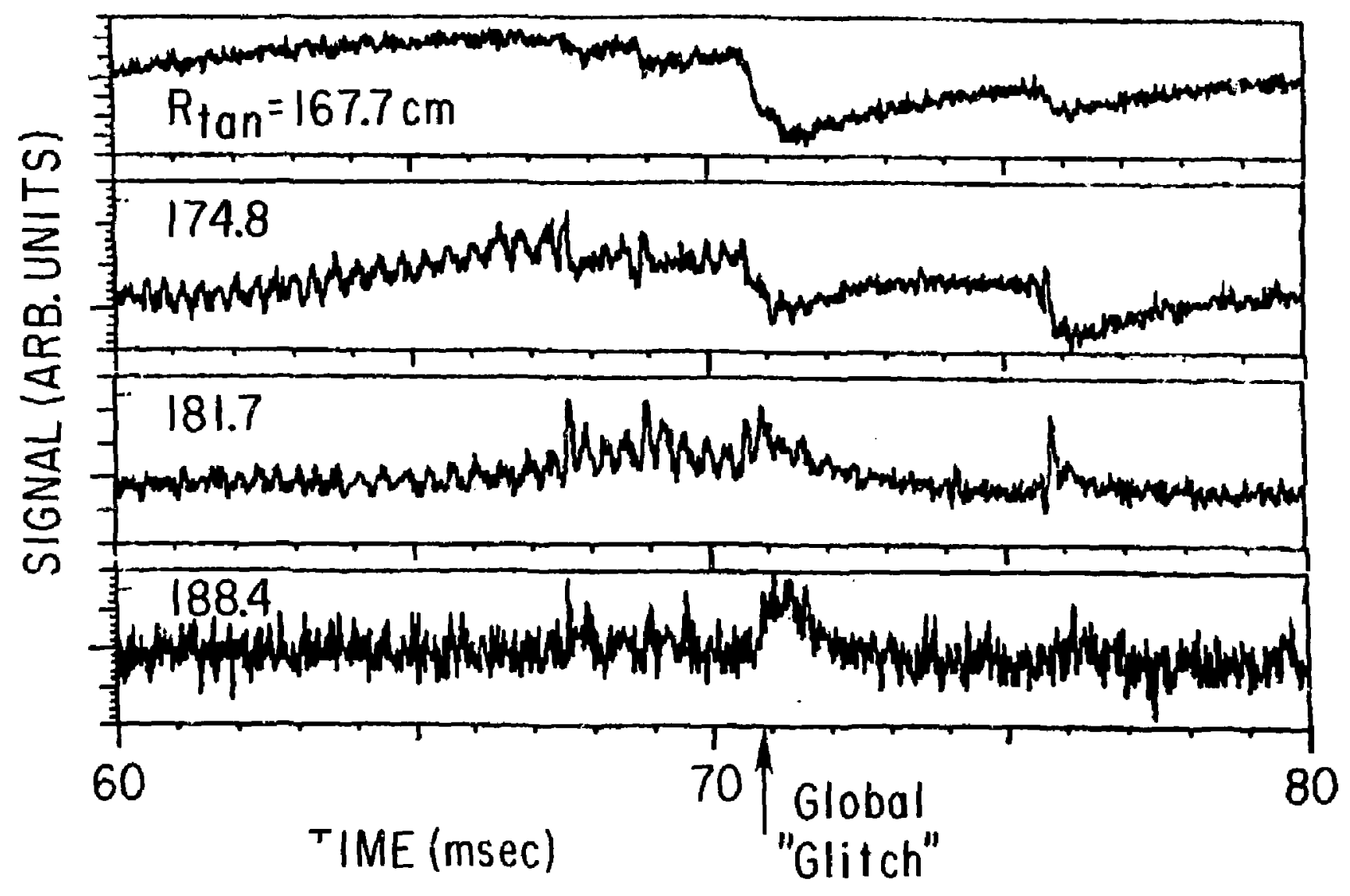




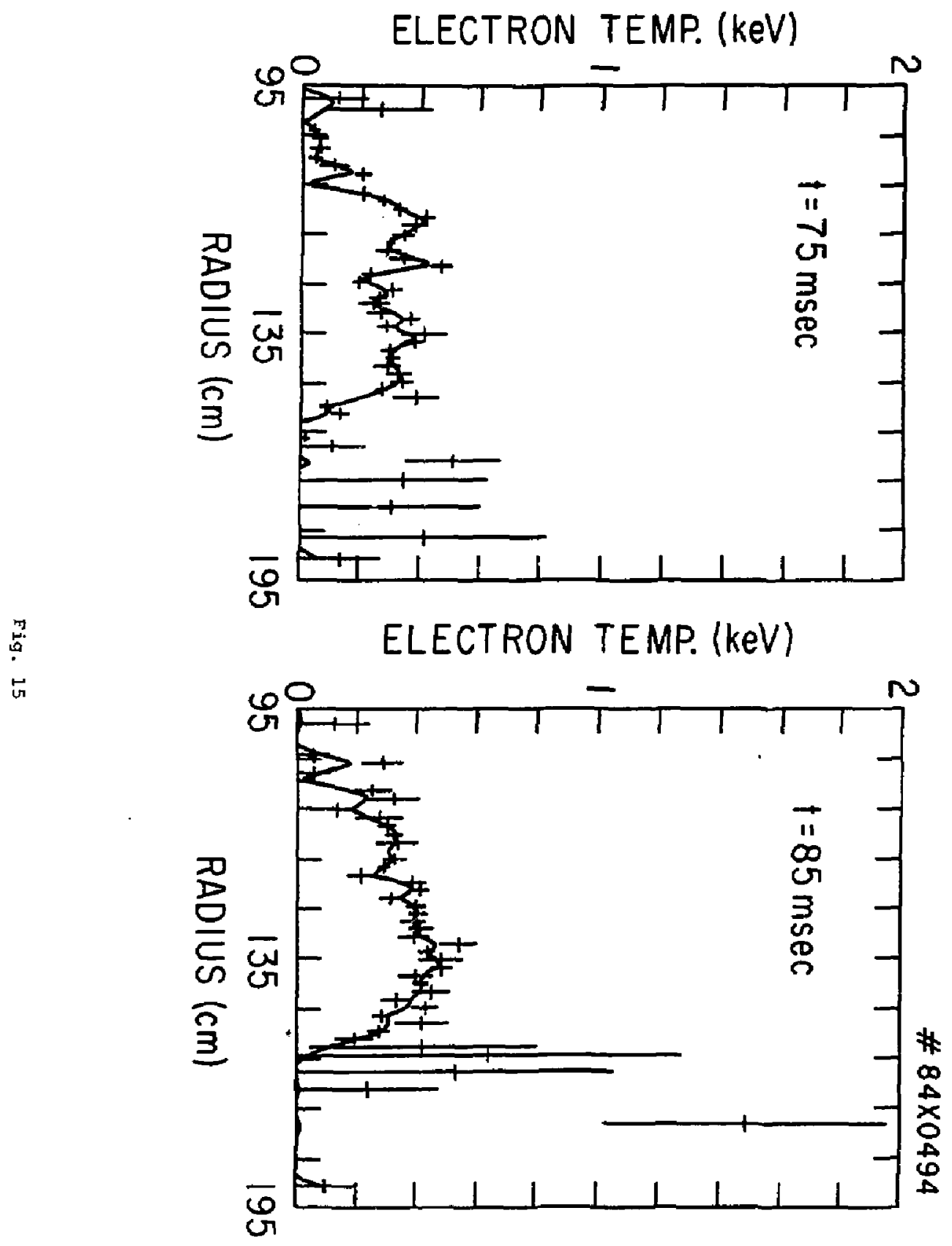



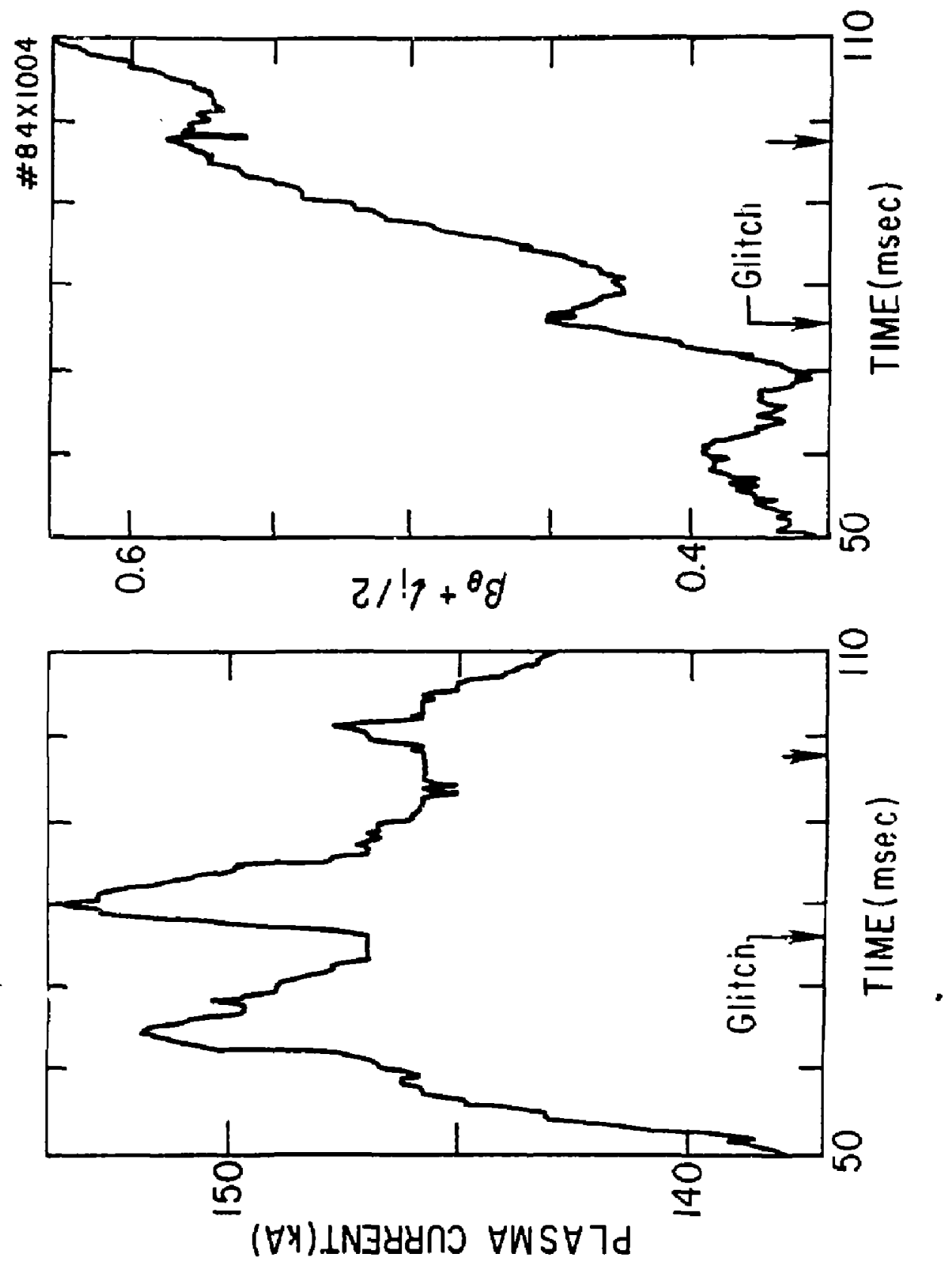

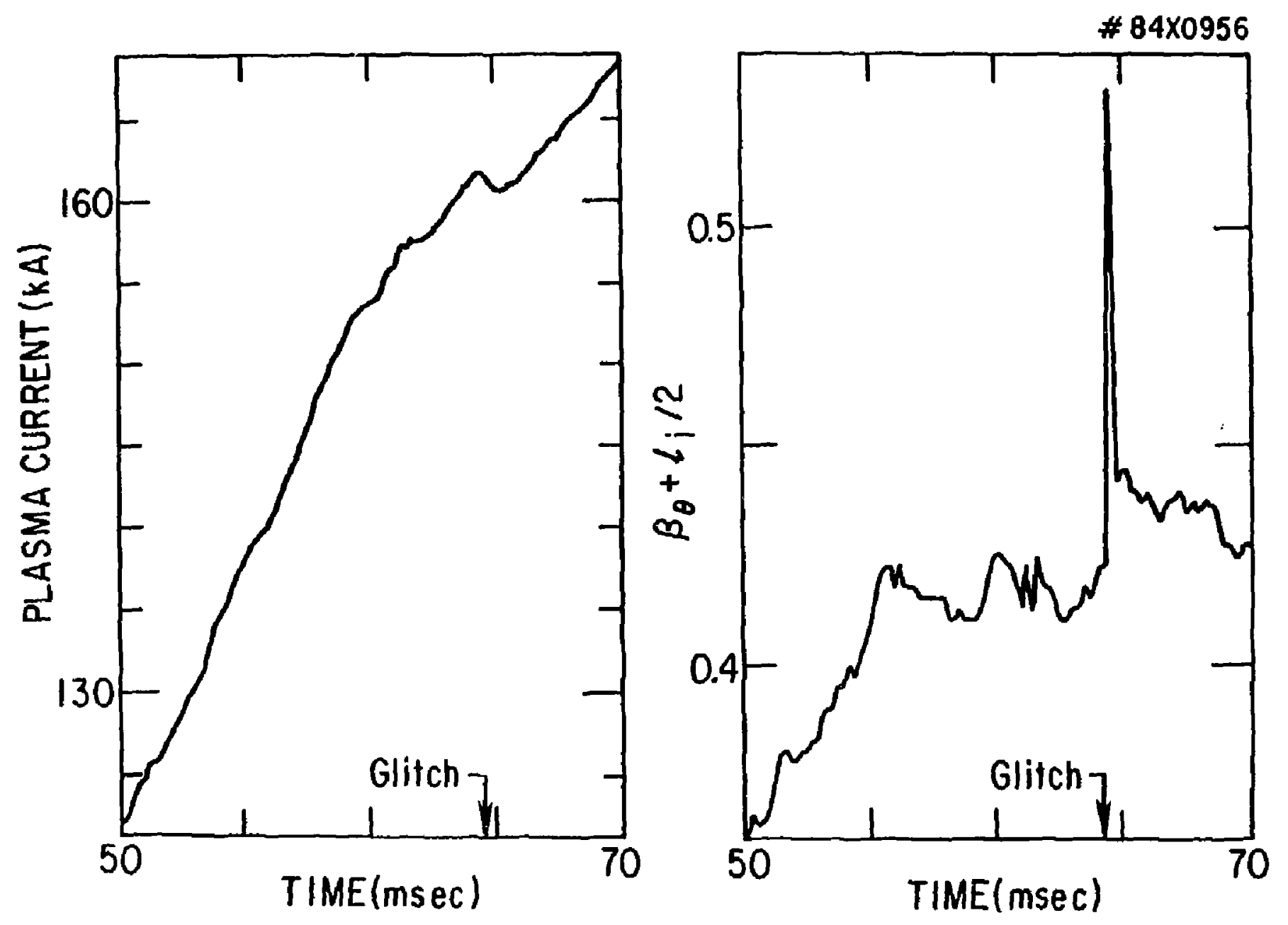

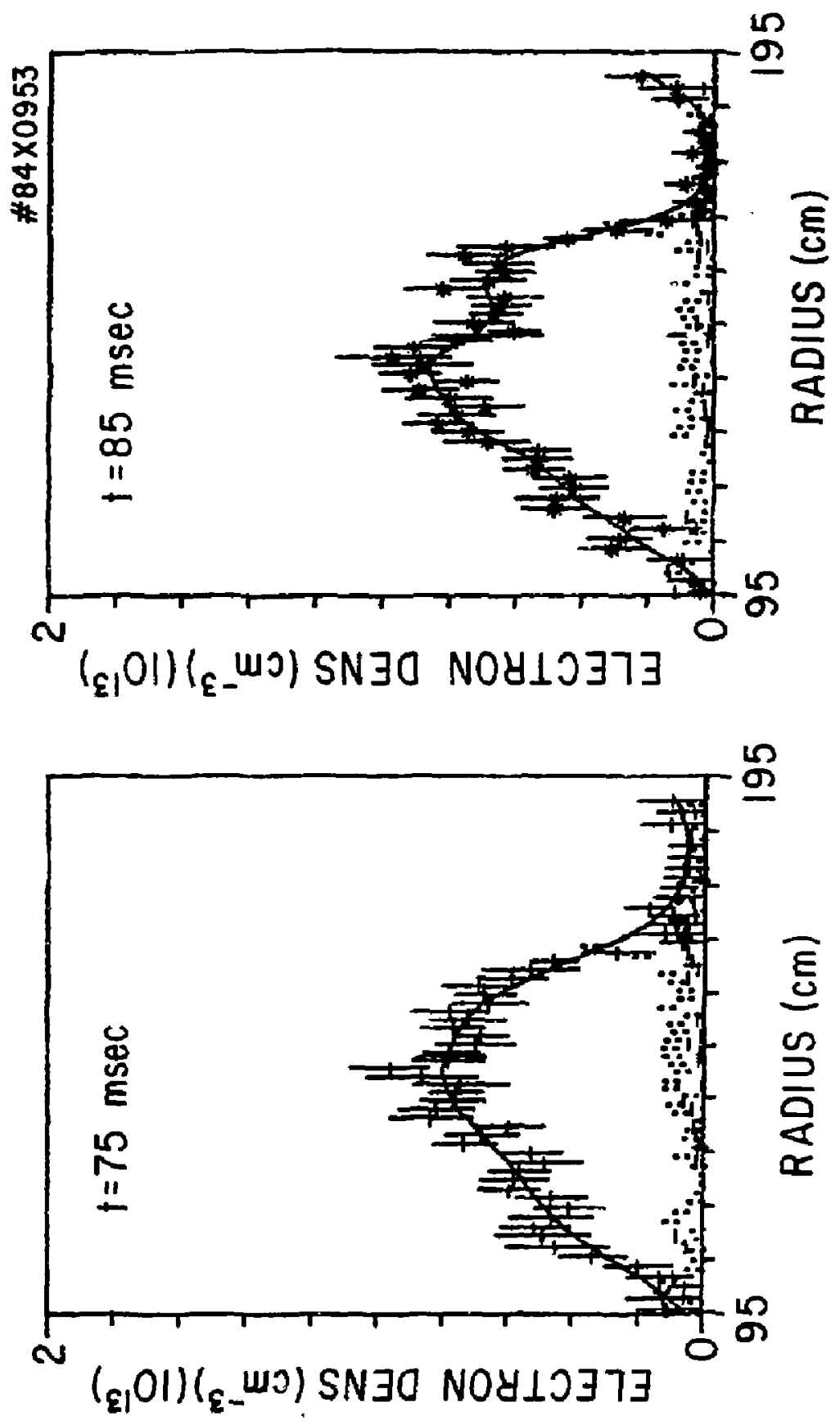


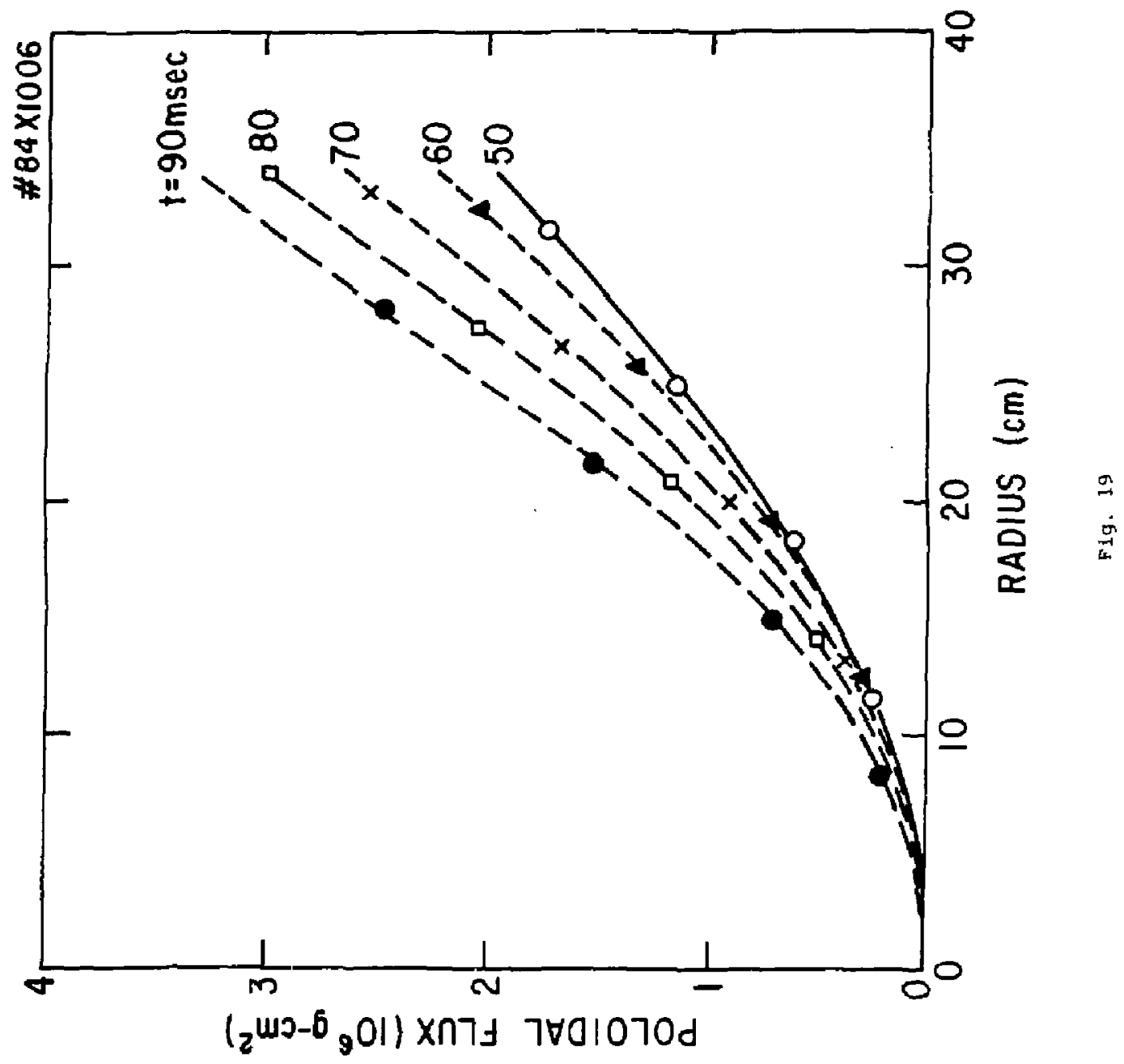




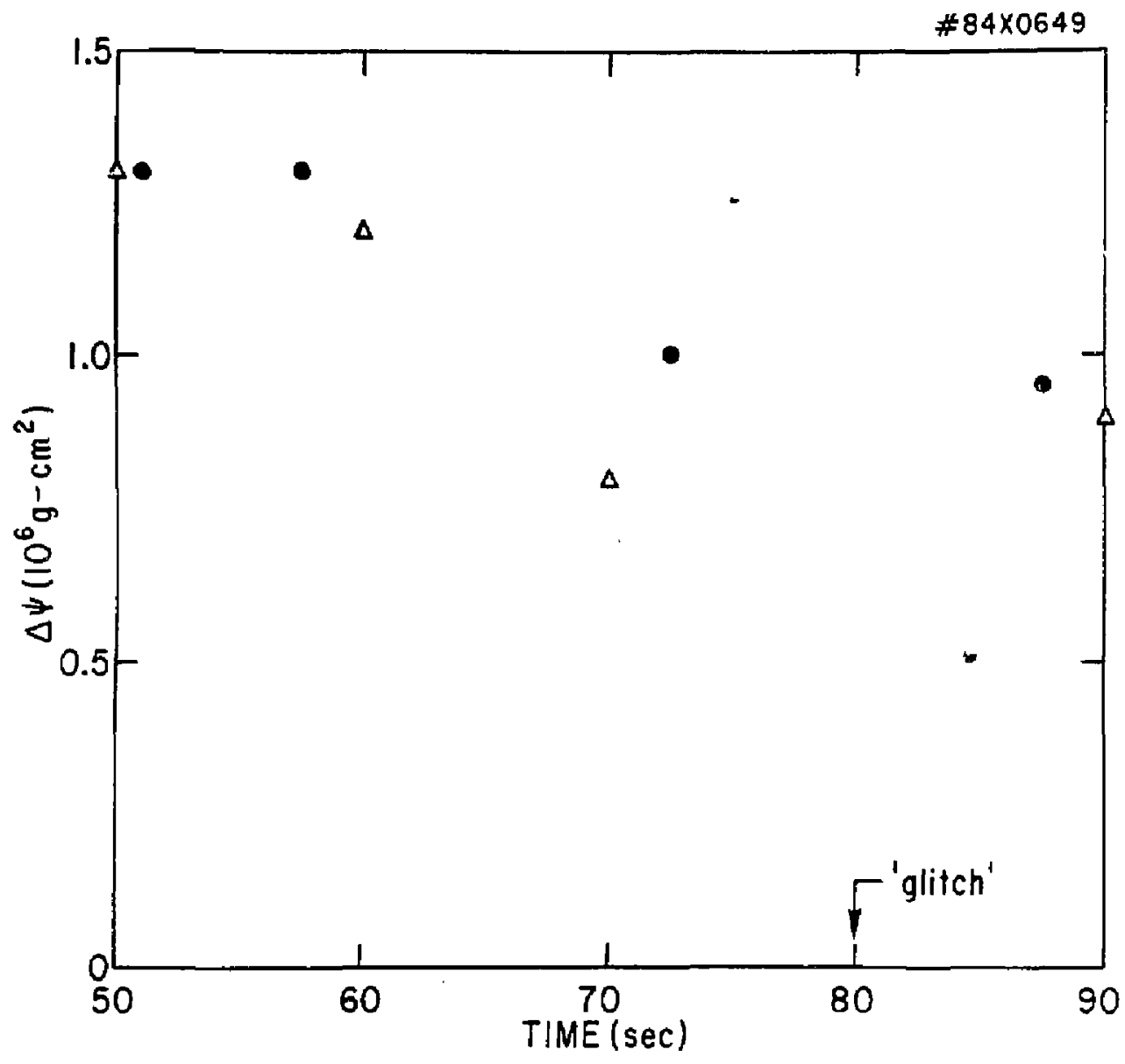

Fig. 20 


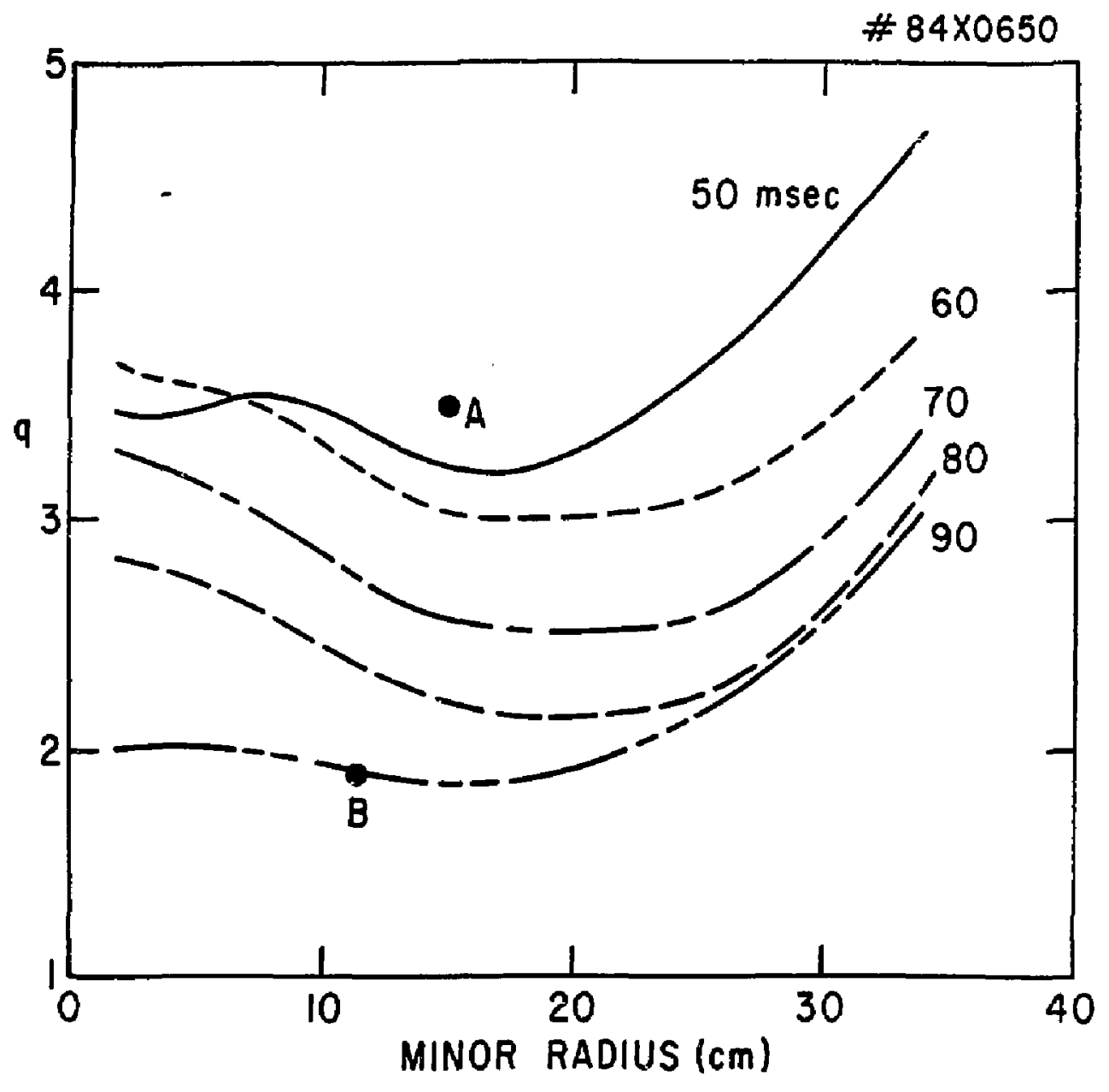

Fig. 21 
Plasme Res Lob, Austra Nat'l Univ, AUSTRal iA Dr. Frena J. Poolonl, Unly ot mollongong, AUSTRALIA Prof. I.R. Jonas, Ftingers Untr., AUSTRALIA Prof. N.H. Erennon, Univ 5yoney. AUSTRALIA Prot. F. Cop, inst Theo Phys, Austala Prof. Fronk Vernoest, Inst theoretische. BELGILM Dr. D. Palumbo, Dg Xl। Fusion Prog, BELGILH Ecole koyale Mitiali: Lat de Phys Plasmas, QELGIuM Dr. P.H, Sakonokg, Un iv Estaud-1. Primzll Dr. C.R. James. Uniy of Al perta, Canada Frot. J. Teichment, Univ of montree 1, Caniada Dr. H,M. Skarsgera, Univ of Seskatenearn, CANADA Prot. S,R, Sreenluasan, Univarslty of Calgery, CANADR Fret. Tudor $h$. Jonnston, INRS-Energle, CANAOA Dr. Honnes Barnerc, Unju aritish Columble, CANed ir. M.F. Bochynskl, MPE Tachnologies, InE., CAMADA Znengmu LI, SH Inst Physles, CHINA

Library. Is ing Hua Univers Ity, CHINk Llorarion, Institute o! Physlcs. China Inst Plasme Phys, Acodemlo Sinlea, GHIM Dr. Peter Lukec, Komenskehc Univ, CZECHOSLOVAKIA The Llorarlen, Cultiant Lebo-atory. ENílaní

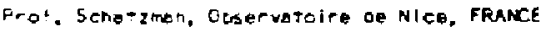
J. RSDET, LEN-BPG, fRANCE AM Dupas LIbrary, AM Dudas LIDraTy, FRANCE Dr. Tom Mual, Acodemy Blbliographic, HDNG KONG Preprint Llorory, Cont kes Inst Phys, Hungary Ir. S.K. Trehan, Panjad Univers/Ty, INDIA Dr. Indra, Monen Lal Das, Benoras HIndu Unlv, JNDIA Jr. L.K. Chavdo, South Gujarat UnIv, I HDIA Dr. R.K. Cnnojiani, Var Rueti Marg. INDIA F. Kam, Physicol Reseerch Lab. INOIA jr. Phillid Rosenel, israe! Inst Tech, ISRAEL Erot. S. Eudermon, Tel Auiv Univers ity. ISRagl Prot. G. Rastagn 1, Unly DI Padow, ITALY Lidererleri, Int'l cte Theo Ponss, ITaly Miss Clolla De Folo, Assog ELARTOMGCNEN, ITMLY EIElioToca, del CNF EURATO., ITAL

Dr. H, Yameto, Tosalde aes a Dev, JRPAN

Fr.ct. M. Yosntkers, JKERI, Toksi Res EsT, JAPAN Frot. T. Uenide, Unlverslity of Tokyo, JAPAN Feseerch into Center. Nagoyo University, JAPAN frot. Kyoji Nishlkbes, Lniv of Hiroshlmo, JAPAN Pret. Sigerw Morl, JKERI, JAPAN

Lbrery, Kyoto University, JAPAH

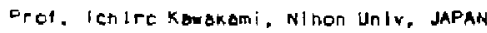

Fre1, Setospil itoh, kyushu Unlverslty, JaPan

Tecn Into Division, Korbe atomic Energy, KOREA DP. R. Englone, Civooc unlversltorla, MExico Givllotheeh, Forr-inst Vigor P Iasmb, NETMERLANDS Prc*. E.S. Lilea, University of walkato, NEW ZEALAND Jr. Surgan C, Snorms, Uible of Colabar, NIGERIA
Prot. J.A.C. Cobrol, Inst Superlor Toch, PORTUGal Or. Detoyion Petrus, ALI CLEA Unlvorslty, Romania Prot. M.A. Mellderg, Unlversity of NbTOI, SC AFRICA Dr. Janan de Villlars. Atomic Enargy Bo, SO AFRICA Fuston Div. LIbrory, JEN, SPAIK Prot. Hohs wilhelimson. Cholmers Un Iv Teeh, SMEDEN Dr. Lennart Stentio, Unlverslty of UAEA, SHEDEN Llorory, Royol Inst Tech, SWEDEN Dr. Erlk T. Karison, UPDSEle Unlvarsitet, SHEOSN Centre de Reenerenesen, Ecole Polytech fod, SwitzERLAND Dr. W. We Ise, Nat'l Bur Stano, USA Dr. W.M. Stacey, Georg inst Tech, USA Or. S.T. Wu, Un iv Alebems, USA Prof. Normen L. Oleson, Unlu 5 Flor lde, USA Or. Banjanin Mo, iona Stote Univ, USA Prot. Magne Kristionsen, Texos Tacr. Univ, WA Dr. Roymend Asker, Auburn unly, usa Dr. V.T. Talok, Khorkor Phys Tech ins, LESE Dr. D.D. Ryutor, SI perlen Acod SCl, USsq De, G,A, Ellsoser, Kur enbtor Ins+1tute, 1552 Dr. $V_{+} A$. Glukhikn, Inst Electro-Physical, ussf Instlitute Gen, Pnysies, USSR

Prot. T.J. Eayd, Univ Colloge Ni males, Males Dr. K. Schindler, Ruhr Univorsltat, w. ECPMANe Nuclear Res Estab, Julloh LTd, M. GERanny Liorarion, Maxthanck institut, w. Gephany Dr. H.J. Koeppler, Unlversity Stuttgort, W. GeamaN Blbllothok, Inst Plasmetorschung, h. Gerama 